\title{
A comparison of metaheuristics for the optimal capacity planning of an isolated, battery-less, hydrogen-based micro-grid
}

\author{
Soheil Mohseni*, Alan C. Brent, Daniel Burmester \\ Chair in Sustainable Energy Systems, School of Engineering and Computer Science, Faculty of Engineering, Victoria University of Wellington, PO Box 600, Wellington 6140, \\ New Zealand
}

\section{H I G H L I G H T S}

- A metaheuristic-based model is proposed to optimally size a hydrogenbased microgrid.

- The microgrid system is equipped with an innovative hydrogen refuelling station.

- The performances of eight metaheuristics are studied in terms of accuracy and speed.

- The moth-flame optimizer is found to outperform the popular algorithms in this area.

- The system's levelized costs of electricity and hydrogen are $\$ 0.09 / \mathrm{kWh}$ and $\$ 4.61 / \mathrm{kg}$.

\section{A R T I C L E I N F O}

\section{Keywords:}

Design optimization

Micro-grids

Smart grids

Metaheuristics

Hydrogen storage

Fuel cell vehicles

\section{G R A P H I C A L A B S T R A C T}

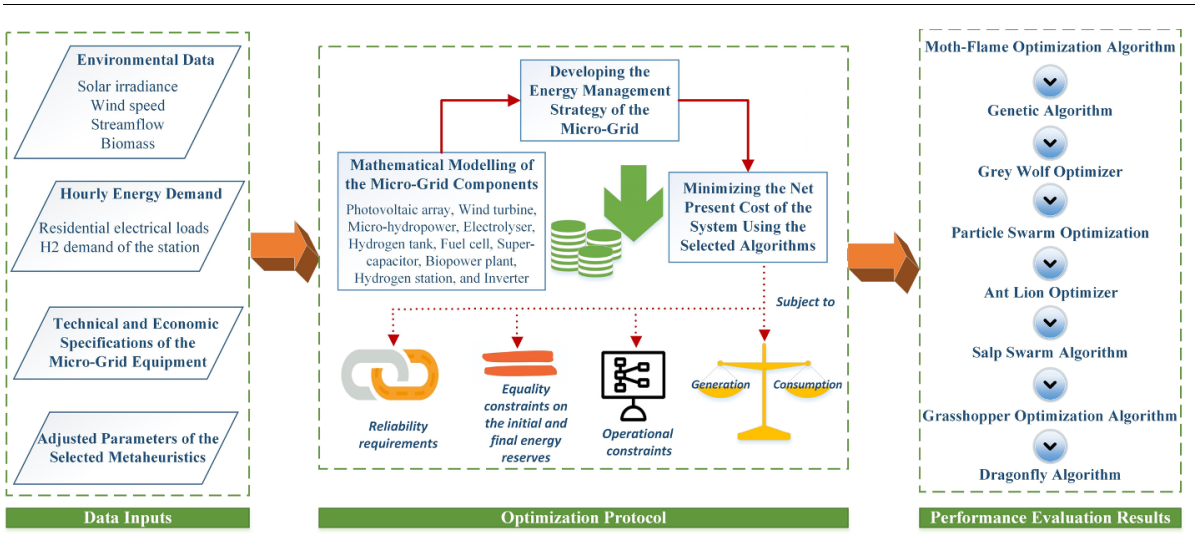

\begin{abstract}
A B S T R A C T
There has been growing interest in the development of sustainable energy systems using the potential of renewable energy sources. However, due to the intermittent nature of renewable energy sources, they must be accompanied by appropriate storage devices to be optimally integrated into so-called smart micro-grid systems. The optimal design problem of sustainable micro-grids is associated with several nonlinearities and non-convexities, and therefore is not amenable to exact methods of optimization. Accordingly, this paper proposes a metaheuristic-based approach for optimizing the size and typology of the components of an off-grid hydrogenbased micro-grid, backed up with super-capacitors and stationary fuel cell systems, in the presence of a hydrogen refuelling station. The paper also compares the performance of six recent metaheuristics. The simulations are carried out for the climatic conditions of the Feilding area, New Zealand using MATLAB. Based on the comparative results, the moth-flame optimization algorithm is found to result in a significant reduction in the total net present cost of the system in comparison with other investigated algorithms. Notably, it outperforms the genetic algorithm and the particle swarm optimization in terms of solution quality by $\sim 2.1 \%$ and $\sim 3.2 \%$ (equating to cost savings of $\$ 123,910$ and $\$ 188,129$ from the target system). The results also demonstrate both the technical feasibility and cost-effectiveness of the proposed stand-alone micro-grid architecture. Particularly, the levelized costs of electricity and hydrogen of the conceptualized system are found to be $\$ 0.09 / \mathrm{kWh}$ and $\$ 4.61 / \mathrm{kg}$, respectively, which are well below the current tariffs in New Zealand.
\end{abstract}

\footnotetext{
* Corresponding author.

E-mail address: soheil.mohseni@ecs.vuw.ac.nz (S. Mohseni).
} 


\author{
Nomenclature \\ Abbreviations \\ ABC artificial bee colony \\ ACO ant colony optimization \\ ALO ant lion optimizer \\ BESS battery energy storage system \\ DA dragonfly algorithm \\ DOE Department of Energy \\ ELF equivalent loss factor \\ GA genetic algorithm \\ GOA grasshopper optimization algorithm \\ GWO grey wolf optimizer \\ $\mathrm{H}_{2} \quad$ hydrogen \\ HGA-MSA hybrid GA-MSA \\ HSA harmony search algorithm \\ HSAA-MFOA hybrid simulated annealing algorithm-MFOA \\ HSSA-MFOA hybrid SSA-MFOA \\ HWC-MFOA hybrid water cycle-MFOA \\ IMFOA improved MFOA
}

$\begin{array}{ll}\text { MFOA } & \text { moth-flame optimization algorithm } \\ \text { MG } & \text { micro-grid } \\ \text { MHOA } & \text { metaheuristic optimization algorithm } \\ \text { MHPP } & \text { micro-hydro power plant } \\ \text { MSA } & \text { moth swarm algorithm } \\ \text { LA } & \text { lead-acid } \\ \text { LCOE } & \text { levelized cost of energy } \\ \text { Li-ion } & \text { lithium-ion } \\ \text { NFL } & \text { no-free-lunch } \\ \text { NP-hard } & \text { non-deterministic polynomial-time hard } \\ \text { NPC } & \text { net present cost } \\ \text { O\&M } & \text { operation and maintenance } \\ \text { PEM } & \text { polymer electrolyte membrane } \\ \text { PSO } & \text { particle swarm optimization } \\ \text { PtG } & \text { power-to-gas } \\ \text { PV } & \text { photovoltaic } \\ \text { RES } & \text { renewable energy source } \\ \text { SC } & \text { super-capacitor } \\ \text { SSA } & \text { salp swarm algorithm } \\ \text { TGA-MFOA time-constrained GA-MFOA } \\ \text { WT } & \text { wind turbine }\end{array}$

\section{Introduction}

Distributed renewable and sustainable energy systems have been proposed as an intervention to overcome many of the challenges associated with large-scale, centralized power generation, such as: high power losses, high emissions (if based on fossil fuel), excessive water use (in thermal power plants), extensive land use (to transmit power), hazardous waste generation (if based on nuclear power), and expensive capital infrastructure [1]. However, the inherent intermittency associated with renewable energy sources (RESs), notably from solar and wind resources, lowers the reliability of the power supply and imposes extra costs on suppliers and/or consumers, and, thereby, hinders the large-scale adoption of them, especially for off-grid applications [2]. A potential solution to facilitate the massive integration of fluctuating RESs into the energy systems is the deployment of micro-grids (MGs) under the smart grid paradigm. The US Department of Energy (DOE) defines the MG as "a group of interconnected loads and distributed energy resources within clearly defined electrical boundaries that acts as a single controllable entity with respect to the grid, which can connect and disconnect from the grid to enable it to operate in both grid-connected or island-mode." Despite this definition, it is commonly discussed that this terminology can also be applied to the case of isolated MGs with no connection to the upstream distribution grid [3].

\section{1. $M G$ design and planning background: Problem characteristics and gaps in knowledge}

The optimal capacity planning problem of the components of a sustainable MG is a combinational optimization problem, which is subject to several sources of non-convexities and nonlinearities [4]. Techniques to solve this problem are subject to high overheads. The reason is that the number of required simulation runs increases drastically with an increasing number of optimization (decision) variables and constraints (which is the case in the optimal capacity planning problem of MGs). Hence, finding a feasible technique to select the optimal sizes of the components accurately and efficiently has been the focus of the attention for MG designers over the last two decades. Accordingly, several optimization techniques are employed in the literature, which can be classified into two categories: (i) mathematical optimization methods, such as integer and linear programming, and (ii) nature-inspired metaheuristic optimization algorithms (MHOAs), which can be sub-categorized into the swarm-based and evolution-based algorithms [5].

Exact mathematical optimization methods are subject to some constraints (e.g. the continuity and derivability of the objective function), follow rigorous procedures, and are usually associated with inflexibility and inability to track the dynamic changes. Therefore, these methods are rarely used today for the optimal planning of renewable and sustainable energy systems. Contrariwise, MHOAs are frequently used to solve the optimal capacity planning problem of a variety of MG structures - which could be looked upon as a power engineering decision-making problem [6]. These algorithms are free from the drawbacks associated with exact optimization techniques and are very simple to implement [7]. Although such stochastic techniques do not ensure the global optimality of the solution acquired, their superior efficiency over the exact methods in the research area of MG investment planning is validated both empirically and conceptually [5].

The first systematic study on the use of MHOAs for the MG sizing was carried out in 2007 by Hakimi et al. [8], where the authors have reported the advantages of the particle swarm optimization (PSO) over classical optimization approaches in this research area. Following their seminal study, many attempts have been made to investigate the potential of utilizing MHOAs for solving the optimum design and equipment capacity planning problem of MGs. In this context, Li et al. [9] have utilized the genetic algorithm (GA) to optimally design an off-grid MG integrating photovoltaic (PV) panels, battery modules, a hydrogenbased back-up system, a solar heating system, a heat boiler, an air conditioner, an absorption heat chiller, and a heat storage system to serve the electrical, thermal, cooling, and hydrogen load demands of a remote community. Ghorbani et al. [10] have gone further and revealed the outperformance of the hybrid GA-PSO over the basic GA and PSO in terms of the quality of design solution sets using an isolated MG testcase system. Derakhshan et al. [11] have employed the cuckoo search optimization algorithm to optimize the design parameters of an on-grid PV/wind turbine (WT)/battery MG. Chauhan and Saini [12] have used the harmony search algorithm (HSA) for the optimal investment planning of an islanded MG comprising of PV panels, WTs, a biogas digester system, a biomass gasifier system, and micro-hydro power plants (MHPPs) as renewable power generation technologies. Nasiraghdam and Jadid [13] have utilized the artificial bee colony (ABC) technique to optimally size a PV/WT/fuel cell renewable energy system and have shown its advantages over the standard GA and PSO approaches in terms of nearing the global optima. Fetanat and Khorasaninejad [14] have adopted the ant colony optimization (ACO) for the optimal 
capacity planning of a classic PV/WT/battery MG and demonstrated its advantages over the $\mathrm{ABC}$ and the GA techniques in terms of reducing the computational burden, whilst preserving the solution quality. A comprehensive review and comparison of MHOAs applied to the MG design optimization can be found in [5].

In the literature, there are also a number of research studies that adapt the existing MHOAs to suit the MG sizing problems. For example, Kefayat et al. [15] have made further progress in optimally designing MGs by combining the $\mathrm{ABC}$ and the ACO algorithms and validating its superior performance over the classic $\mathrm{ABC}$ and ACO approaches in terms of both computational expensiveness and solution efficiency through a number of test-cases. Furthermore, Mohandas et al. [16] have combined the $\mathrm{ABC}$ algorithm with chaos theory and, through applying it to the optimal sizing problem of distributed generation units in a representative distribution system, asserted its primacy over the standard $\mathrm{ABC}$ algorithm in the context of their study. As another example, Jiao et al. [17] have improved the basic HSA to expand its search space range as well as to enhance the interaction between its local and global search procedures. By applying their proposed modified HSA to the optimal planning problem of a grid-independent MG, the authors have proved the supremacy of the modified HSA over the classic HSA and PSO techniques, which have been considered as benchmark algorithms. Sheng and Zhang [18] have also proposed an improved binary bat algorithm to solve the MG capacity planning problem. They have also demonstrated the superiority of their algorithm over the basic binary bat algorithm, the GA, and the PSO. A fundamental problem with making such inferences in this category of previous studies, is that they offer no insight into why certain algorithms are selected to be modified in the first place. We believe that this is a serious criticism of all the previous studies that fall in this group. Also, it is worthwhile noting that since the GA and the PSO are the most documented algorithms in this research area, they are usually used as reference algorithms to examine the performance of other algorithms [5].

Although many MHOAs have already been suggested to solve the size optimization problem of MGs, there is still a considerable number of the state-of-the-art MHOAs, whose potentials have not yet been explored in this research area [7]. This is important, since a seemingly small reduction in the sizes of the components of a smart MG may substantially reduce its whole-life cost. Also, the reason that a newly emerged MHOA might outperform those previously applied in the study of MG optimal capacity planning lies in the ever-evolving nature of MHOAs and the so-called no-free-lunch (NFL) theorem [19]. The theorem analytically demonstrates the inability to generalize findings on the performances of the metaheuristics from a specific problem across various research areas and disciplines, thereby, creating the dual opportunities to propose new metaheuristics and evaluate their efficiencies in solving diversified non-deterministic, polynomial-time hard (NP-hard) problems.

On the other hand, from the MG structure point of view, most studies have tended to focus on battery energy storage systems (BESSs) to back up the variable renewable energy supplies [20]. Although BESSs are widely envisioned for long-term (seasonal) energy storage applications in an implicit fashion (since usually no provision is made to avoid the long-term storage of energy), most types of them are ineffective for seasonal energy storage due to their high self-discharge rates, especially if they are placed under high stresses [21]. In addition, the types of BESSs that are associated with lower self-discharge rates (typically lead-acid (LA) batteries) are, indeed, not as clean as they are often conceived. This has led researchers to investigate other competing energy storage technologies. In this respect, an intriguing area in the field of renewable and sustainable energy systems is to exploit the potential of stationary power-to-gas (PtG) facilities for long-term energy storage applications. However, most studies dealing with the integration of PtG technologies into the configuration of MGs in the planning phase have failed to consider the transient stability requirements of the systems. This is a shortfall, because, obviously, dissimilar investment assessments might arise if dynamic stability constraints (which are of prime importance to ensure the resilient operation of the grid-independent MGs in practice) are considered.

\subsection{Contributions of the study}

Based on the above discussion, the main contributions of this paper are:

1. A generic metaheuristic-based optimal design and equipment capacity planning model is proposed for stand-alone MGs, and the performances of six recently developed MHOAs are assessed and compared with the results obtained by most popular metaheuristics in the field of MG planning, in terms of solution accuracy and computational intensiveness.

2. A test-case hydrogen-based MG structure is suggested, providing a highly economical, effective, multi-vector, flexible, sustainable energy system to electrify remote communities. The conceptualized stand-alone MG configuration also secures the dynamic stability of the system by accelerating the system transient response time compared with the existing hydrogen-based MG architectures, thereby enhancing the resilience of power supply for stand-alone applications.

3. A mechanism is devised, for the first time, to efficiently integrate hydrogen fuel cell-powered trucks and tractors, as a newly emerging energy demand category in the transport sector, into sustainable energy systems to help move towards the goals of agricultural and transport sustainability.

\subsubsection{Selected metaheuristic optimization algorithms}

The following six recently developed metaheuristics are separately employed in the proposed optimal planning approach: (i) the mothflame optimization algorithm (MFOA) [22], (ii) the dragonfly algorithm (DA) [23], (iii) the salp swarm algorithm (SSA) [24], (iv) the ant lion optimizer (ALO) [25], (v) the grey wolf optimizer (GWO) [26], and (vi) the grasshopper optimization algorithm (GOA) [27]. In addition, the two most well-known and widely used MHOAs in this research area, i.e. the GA $[28,29]$ and the PSO [30], are embedded in the optimal design and capacity planning approach separately. Then, the performances of the above-mentioned algorithms are compared with each other in terms of both convergence rate and quality of the obtained solution set. It must be recalled that the GA and the PSO can be considered as the reference algorithms in this analysis, since their proper performances are widely recognized and acknowledged in the literature of MG design and capacity planning [31].

\subsection{Outline of paper}

The remainder of this paper is organized as follows. Section 2 introduces the structure of the hydrogen-based MG used as a test-case system for the comparison of the performances of different MHOAs. The utilized metaheuristic-based approach to optimize the size and typology of the MG components is presented in Section 3. Section 4 reports the results and the discussion. Section 5 draws our conclusions. Finally, the limitations of this study and the areas for potential future research are presented in Section 6.

\section{System under study}

This section first describes the structure and power flow of the suggested off-grid hydrogen-based MG, which is used as a test-case system to verify the efficacy of the proposed metaheuristic-based approach, and to compare the performances of the aforesaid MHOAs in optimally calculating the size and typology of the components of MGs. It then presents the mathematical modelling of the test-case system's components. Finally, it discusses the strategy adopted in the model to 
operate the studied MG.

\subsection{Structure and power flow of the conceptualized off-grid $M G$}

The topology and the flow of energy through the components of the conceptualized autonomous hydrogen-based MG test-case system are represented schematically in Fig. 1. The black arrows in the figure represent the electricity power lines, while the red arrows represent the hydrogen gas pipelines. The conceptualized MG test-case system in this study consists of PV panels, WTs, micro-hydro turbines, a fuel cell, an electrolyser, a hydrogen tank, compressors, power converters, supercapacitors (SCs), a biopower plant, a DC dump load, and a hydrogen refuelling station utilized to address the energy demands of hydrogen fuel cell-powered trucks and tractors. The unidirectional converters employed in the system connect the power/hydrogen generation components as well as the residential loads to a common DC bus of 120 VDC, which has been noted to be a promising standard voltage for DC MGs in [32], while the bidirectional converter couples the SC bank to the MG network.

\subsection{Mathematical modelling of the MG components}

\subsubsection{PV panels}

The Canadian Solar CS6U-325P polycrystalline PV panel, which has a rated power of $325 \mathrm{~W}$ is employed in this study [33]. The power output from the PV generator $(\mathrm{kW})$ at time step $t$ can be determined using Eq. (1) [10].

$P_{P V}(t)=N_{P V} \times \eta_{g} \times A_{m} \times G(t)$,

where $N_{P V}$ is the optimum number of PV panels calculated at each optimization iteration; $\eta_{g}$ is the total PV generation system's efficiency (i.e. 15\%), which takes into account the DC/DC power conversion efficiency; $A_{m}$ represents the area of each panel (i.e. $1.92 \mathrm{~m}^{2}$ ); and $G(t)$ denotes the aggregate solar irradiance on the tilted PV panels $\left(\mathrm{kW} / \mathrm{m}^{2}\right)$ at time step $t$.

\subsubsection{Wind turbines}

The Fuhrländer FL30 and FL100 AC WTs are considered in this study. The power output from the wind generator at each time step can be determined by multiplying the optimum number of each WT type, i.e. calculated at each optimization iteration, by its output power, approximated from the respective power-speed characteristic curves

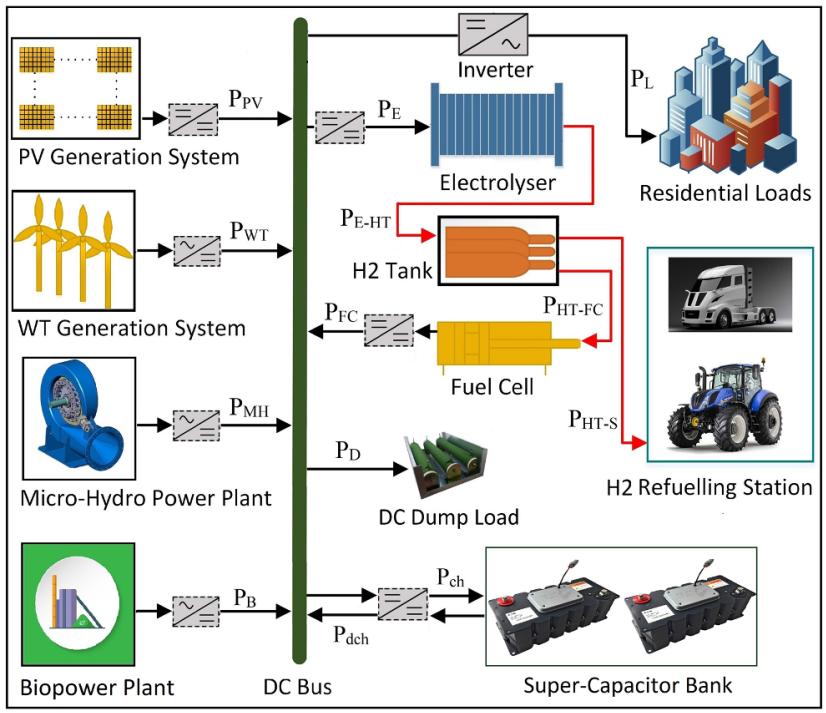

Fig. 1. Schematic representation of the conceptualized islanded hydrogenbased micro-grid.

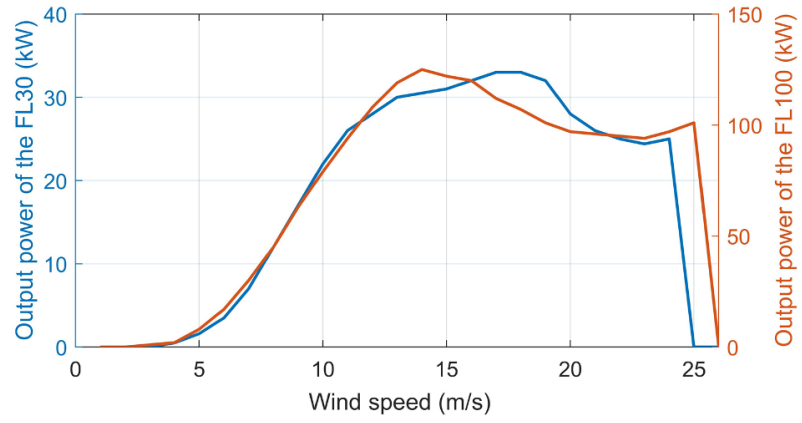

Fig. 2. Characteristic curves of the Fuhrländer FL30 and FL100 WTs [34].

shown in Fig. 2, which take into account the efficiency of the AC/DC converter [34].

Furthermore, the following equation can be used to estimate the wind speed at the turbine hub altitude $(h)$ [35]:

$V_{h}=V_{\text {ref }} \times\left(\frac{h}{h_{\text {ref }}}\right)^{\gamma}$,

where $V_{r e f}$ is the reference speed measured at the height of $h_{r e f}$, and $\gamma$ is a number between 0.1 and 0.25 depending on the status of terrain, which is equal to 0.25 for the non-flat, tree-covered land area of the considered case study site. Moreover, the turbine hub altitudes for the FL30 and FL100 WTs are equal to 27 and $38 \mathrm{~m}$, respectively.

\subsubsection{Micro-hydro power plants}

The Natel FreeJet FJ-7A MHPP is utilized in this paper to generate power with a run-of-river scheme, which has a rated power of $49 \mathrm{~kW}$. The power output from the micro-hydro power system (kW) at time step $t$ can be obtained using Eq. (3) [36].

$P_{M H}(t)=N_{M H} \times \rho \times h \times g \times \eta_{M H} \times \frac{F(t)}{1000}$,

where $N_{M H}$ is the optimum number of MHPPs (i.e. micro-hydro turbines) determined at each optimization iteration, $\rho$ is the water density (i.e. $1000 \mathrm{~kg} / \mathrm{m}^{3}$ ), $h$ is the gross head height (i.e. $7 \mathrm{~m}$ ), $g$ is the acceleration of gravity (i.e. $\left.9.81 \mathrm{~m} / \mathrm{s}^{2}\right), \eta_{M H}$ is the total efficiency of MHPPs and the AC/DC converter (i.e. 55\%), and $F(t)$ is the hourly streamflow at time step $t\left(\mathrm{~m}^{3} / \mathrm{s}\right)$.

\subsubsection{Hydrogen sub-system}

The generic hydrogen sub-system considered in this study, consists of a polymer electrolyte membrane (PEM) electrolyser, an intermediary-pressure compressor, a generic hydrogen tank, and a PEM fuel cell. All the components of the hydrogen sub-system are considered to be generic products, the technical and economic specifications of which were obtained from [33] and [37].

The hydrogen power delivered from the electrolyser to the hydrogen tank at each time step can be obtained as follows:

$P_{E-H T}(t)=P_{E}(t) \times \eta_{E}$,

where $\eta_{E}$ is the total efficiency of the electrolyser, the DC/DC converter, and the intermediary-pressure compressor, i.e. $60 \%$. The compressor is utilized to compress the hydrogen produced by the electrolyser at around 1.2 bar pressure to approximately 20 bar.

The energy content of the hydrogen stored in the reservoir at each time step can be determined as:

$E_{H T}(t)=E_{H T}(t-1)+\left(P_{E-H T}(t)-\frac{\left(P_{H T-F C}(t)+P_{H T-S}(t)\right)}{\eta_{\text {tank }}}\right) \times \Delta t$,

where $P_{H T-F C}(t)$ is the delivered hydrogen power from the hydrogen tank to the fuel cell at time step $t ; P_{H T-S}(t)$ is the delivered hydrogen 
power from the reservoir to the refuelling station at time step $t ; \eta_{\text {tank }}$ represents the round-trip efficiency of the tank, i.e. $95 \%$; with $\Delta t$ denoting the time step increment, i.e. $1 \mathrm{~h}$.

Then, the mass of stored hydrogen at each time step, which has been considered as a decision variable, can be calculated by the following equation:

$m_{H T}(t)=\frac{E_{H T}(t)}{H H V_{H 2}}$,

where $H H V_{H_{2}}$ is the higher heating value of the hydrogen, i.e. $39.7 \mathrm{kWh} / \mathrm{kg}$.

Finally, the output power of the fuel cell at each time step can be obtained by:

$P_{F C}(t)=P_{H T-F C}(t) \times \eta_{F C}$,

where $\eta_{F C}$ represents the electrical efficiency of the fuel cell considering the efficiency of the DC/DC converter, which connects it to the DC bus of the MG, which is considered as $40 \%$.

\subsubsection{Super-capacitor bank}

An SC bank, whose optimum number of SC modules is under investigation, is included in the structure of the conceptualized MG testcase system in order to: (i) improve the transient stability of the system, and (ii) avoid significant degradation of the adopted PEM fuel cell by mitigating its start-stop cycles, as well as its start-up and shut-down processes. The energy content of the SC bank at time step $t$ can be calculated by:

$E_{S C}(t)=E_{S C}(t-1)+\left(P_{c h}(t)-\frac{P_{d c h}(t)}{\eta_{S C}}\right) \times \Delta t$,

where $\eta_{S C}$ represents the round-trip efficiency of the SC modules taking into account the efficiency of the bidirectional DC/DC converter tying them to the MG's network (i.e. 95\%); while $P_{c h}(t)$ and $P_{d c h}(t)$ denote the charging and discharging powers of the SC bank at time step $t$, respectively.

The MAXWELL EDLC SC modules with a capacitance of $3500 \mathrm{~F}$ (i.e. equivalent to $\sim 3.23$ Wh considering a maximum current of $1500 \mathrm{~A}$ ) are put into service in this study, whose voltage levels can fluctuate within the range $0.8-2.7 \mathrm{~V}$ [38].

\subsubsection{Biopower plant}

The biomass power plant considered in this paper comprises of an anaerobic digestion reactor, a methane reformer, an air separation plant, and an internal combustion engine, as an integrated unit, whose optimal electricity generation capacity is under question.

The anaerobic digestion reactor initially utilizes the wet (low-grade) biomass - forest foliage, grasses, agricultural crop residues, aquatic biomass, and so forth - to produce methane gas. The reformer then uses the methane gas to produce pure hydrogen gas through a steam reforming process at high temperatures between 900 and $1000{ }^{\circ} \mathrm{C}$. Ultimately, the hydrogen is burned in oxygen, purified out of the air using the air separation plant, in the internal combustion engine to generate carbon-free power. Notice that water is the only product of the combustion of hydrogen in oxygen. The overall waste $(\mathrm{kg})$ to power $(\mathrm{kW})$ efficiency of the conceptualized biopower plant, taking into consideration the efficiencies of the digestion reactor, the methane reformer, and the hydrogen-fuelled internal combustion engine, is expected to be $3.47 \%$, quantified by multiplying the efficiency of the unified reactor-reformer system put forward by Hakimi and Moghaddas-Tafreshi [39], i.e. $4.54 \%$, by the efficiency of the hydrogen internal combustion engine devised by Yamada and Mohamad [40], i.e. $85 \%$, and then by the efficiency of its relevant DC/DC converter, i.e.
$90 \%$ [37]. Moreover, it is assumed that the low-grade waste is supplied to the biopower plant on a consistent basis, in accordance with the available amount of biomass on each day, leading to a flat daily power output curve for the plant.

\subsubsection{Hydrogen refuelling station}

The hydrogen station infrastructure is utilized to power fuel cell trucks and tractors. It is mainly comprised of a high-pressure compressor (20 to 350 bar), a pre-cooling system, and a dispenser to deliver the fuel. In order to adequately size such equipment, the output hydrogen power of the station $\left(\mathrm{kg} \mathrm{H}_{2} / \mathrm{h}\right)$ is used as a decision variable. In this study, a generic hydrogen filling station is considered, the efficiency of which is denoted by $\eta_{S}$, which is considered as $95 \%$.

Furthermore, the New Holland's NH2 fuel cell-powered tractor and the Hyundai commercial heavy-duty fuel cell-electric truck, which respectively hold 8.2 and $32.86 \mathrm{~kg}$ of hydrogen at a pressure of $350 \mathrm{bar}$ in their type IV carbon composite-based reservoirs, are considered to be the hydrogen-powered vehicles that utilize the station $[41,42]$.

\subsubsection{DC/AC inverter for residential loads}

Unlike the other converters used in the system, the capacity of this inverter is not dependent on the size of its corresponding components, and, therefore, it is the only converter that takes part in the optimal planning procedure in an unsupervised fashion. A generic single-phase DC/AC inverter is considered in this study, the efficiency of which is represented by $\eta_{I}$, i.e. $95 \%$.

\subsection{Operating strategy of the $M G$}

The proposed optimal planning approach adopts a cycle-charging energy dispatch strategy, as described in detail in the following subsections. In this paper, a low-pass energy filter is employed to divide the surplus/shortage of energy production into the high- and low-frequency components, inspired by Akram et al. [43], who have found this technique to be effective for the optimal sizing of a hybrid battery-SC energy storage system to be integrated into a grid-tied MG. Then, the high-frequency component of the surplus/shortage of energy production is injected to/drawn from the SC bank, while the hydrogen subsystem takes the responsibility to absorb/supply the low-frequency component of the energy excess/shortfall through water electrolysis/ fuel cell power generation. In this manner, the slow dynamic response and low power density of the fuel cell are compensated for, which guarantees the dynamic stability of the system, whilst also providing an efficient, cost-effective, environmentally-friendly energy storage platform for backing up the renewable power generation.

\subsubsection{Power generation meets demand}

In this situation, the power generated by the PV panels, WTs, MHPPs, and the biopower plant satisfies the residential demand for electricity. Accordingly, the power delivered from the DC bus to the electrolyser, the amount of hydrogen produced, the output power of the fuel cell, as well as the charging and discharging powers of the SC bank, are all equal to zero; hence:

$P_{P V}(t)+P_{W T}(t)+P_{M H}(t)+P_{B}(t)=\left(P_{L}(t) / \eta_{I}\right)$,

$E_{H T}(t)=E_{H T}(t-1)-\left(P_{S}(t) / \eta_{S}\right) \times \Delta t$,

where $P_{B}(t)$ represents the output power from the biopower plant at time step $t, P_{L}(t)$ denotes the residential demand for electricity at time step $t$, and $P_{S}(t)$ is the station's demand for hydrogen at time step $t$.

\subsubsection{Over-generation}

If the amount of electricity generated from the renewable sources is 
more than the residential demand for electricity, the low-frequency component of the excess power will be used in the electrolyser for hydrogen production, which will then be stored in the hydrogen tank, while its high-frequency component will be used to charge the SCs; hence:

$P_{E X}(t)=P_{P V}(t)+P_{W T}(t)+P_{M H}(t)+P_{B}(t)-\left(P_{L}(t) / \eta_{I}\right)$,

$P_{E-H T}(t)=P_{E X, L F}(t) \times \eta_{E}$,

$P_{c h}(t)=P_{E X, H F}(t)$,

$E_{H T}(t)=E_{H T}(t-1)+P_{E-H T}(t) \times \Delta t-\left(P_{S}(t) / \eta_{S}\right) \times \Delta t$,

where $P_{E X, H F}(t)$ and $P_{E X, L F}(t)$ represent the high- and low-frequency components of the excess of power generation from renewable sources at time step $t$, respectively.

In this situation, when the hydrogen tank is fully charged or the amount of low-frequency excess power is greater than the capacity of the electrolyser, the DC dump load absorbs the low-frequency excess power. Similarly, when the amount of high-frequency excess power is beyond the rated capacity of the SC bank, it is dissipated in the dump load.

\subsubsection{Over-demand}

In circumstances where there is a shortage of electricity generation capacity to satisfy the residential demand for electricity, the hydrogen will be released from the storage tank and fed to the fuel cell to compensate for the low-frequency component of the shortage of power generation, while the discharging of SCs supplies its high-frequency component; hence:

$P_{S H}(t)=\left(P_{L}(t) / \eta_{I}\right)-P_{P V}(t)-P_{W T}(t)-P_{M H}(t)-P_{B}(t)$,

$P_{H T-F C}(t)=P_{S H, L F}(t) / \eta_{F C}$,

$P_{d c h}(t)=P_{S H, H F}(t)$,

$E_{H T}(t)=E_{H T}(t-1)-P_{H T-F C}(t) \times \Delta t-\left(P_{S}(t) / \eta_{S}\right) \times \Delta t$,

where $P_{S H, H F}(t)$ and $P_{S H, L F}(t)$ denote the high- and low-frequency components of the amount of shortfall in electricity supply at time step $t$, respectively.

Under such conditions, when the amount of low-frequency power shortage exceeds the nominal capacity of the fuel cell, or the hydrogen and typology of the considered hydrogen-based MG components.

The approach minimizes the total net present cost (NPC) of the MG as the optimization criterion, to determine the optimal capacity and/or the number of each component, subject to reliability and operational constraints. The objective function is then minimized iteratively using each of the aforementioned eight MHOAs to determine the optimal size and typology (where applicable) of the MG components. This is followed by operating the system using the obtained sizes at each iteration, so as to check if the imposed operational and reliability constraints are satisfied. Finally, the best-approximated solution set, including the minimum total NPC and the optimum size combination of the components at the last iteration, is reported.

All the investigated metaheuristic algorithms start by creating a matrix of primary random population of particles/individuals (i.e. search agents), which move (evolve) towards the global optima in the $d$-dimensional search (solution) space (in compliance with $d$ design variables subjected to upper and lower bounds, which define the design space of the problem), using their fitness values (values of the objective function) as the evaluation criterion. The procedure of moving (evolution) towards the optimal solution set continues according to the specific rules and operators defined for each optimization algorithm until the maximum number of iterations (i.e. the stopping criterion) is reached. A brief overview of the aforementioned metaheuristics is given as Supplementary Material accompanying the paper (Additional File 1: An overview of the selected metaheuristic optimization algorithms). Furthermore, the detailed pseudo-codes of the above-mentioned algorithms are given as Supplementary Material accompanying the paper (Additional File 2: Algorithms S1-S8).

Since the efficiencies and costs associated with the power converters shown inside the dashed lines in Fig. 1, as well as the compressors employed within the system, are taken into account in their corresponding components, the costs of the dump load are considered to be negligible, and the consideration of the costs associated with cables, power lines, and hydrogen pipelines is outside the scope of this study (since these parameters are very context-specific); therefore, the number and/or the capacity of PV panels, WTs, MHPPs, the fuel cell, the electrolyser, the hydrogen tank, the hydrogen filling station, the biopower plant, SCs, and the residential loads' inverter are considered to be the decision (design) variables.

Based on the above discussion, the total NPC of the MG is composed of the sum of the NPCs of the components, which can be defined as:-

$N P C_{T}=N P C_{P V}+N P C_{W T 1}+N P C_{W T 2}+N P C_{M H}+N P C_{B}+N P C_{F C}+N P C_{E}+N P C_{H T}+N P C_{S}+N P C_{S C}+N P C_{I}+p e n_{c o n s}$,

tank reaches the minimum allowable storage capacity limit, the residential load remains partially/fully unserved. Similarly, when the amount of high-frequency power shortfall outpaces the amount of the stored energy in the SC bank, some of the residential loads must be shed. Moreover, under any of the conditions illustrated above, if refuelling the hydrogen fuel cell-powered vehicles leads to a hydrogen storage level below the desired lower limit (as specified in the next section), or in other words, if the amount of hydrogen stored in the tank is not adequate for addressing the hydrogen demand of the station (if there is any), a hydrogen load shedding mechanism preserves the stability of the MG network.

\section{Metaheuristic-based optimal design approach}

This section presents the mathematical formulation of the proposed metaheuristic-based approach developed to determine the optimal size where $N P C_{P V}, N P C_{W T 1}, N P C_{W T 2}, N P C_{M H}, N P C_{B}, N P C_{F C}, N P C_{E}, N P C_{H T}$, $N P C_{S}, N P C_{S C}$, and $N P C_{I}$ represent the NPCs of PV panels, FL30 WTs, FL100 WTs, MHPPs, the biopower plant, the fuel cell, the electrolyser, the hydrogen tank, the hydrogen refuelling station, SCs, and the inverter for residential loads, respectively, each of which can be calcu-

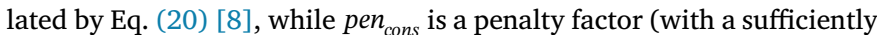
large value) that is applied to the solutions that violate any of the imposed operational and planning constraints - owing to the fact that the problem has been formulated as a single-objective optimization problem.

$N P C=N \times\left(C C+R C \times K+O \& M \times \frac{1}{C R F(d, R)}-S V\right)$,

where $C C, R C$, and $O \& M$ represent the capital, replacement, and operation and maintenance costs, respectively; $S V$ denotes the salvage value (applicable to the components with longer lifetimes than the 
planning horizon); and $C R F$ and $K$ are the capital recovery and single payment present worth factors, respectively, which can be calculated using Eqs. (21)-(23) [8].

$C R F(d, R)=\frac{d(1+d)^{R}}{(1+d)^{R}-1}$,

$K=\sum_{n=1}^{Y} \frac{1}{(1+d)^{L \times n}}$

$Y=\left\{\begin{array}{l}{\left[\frac{R}{L}\right]-1 ; \text { if } R \text { is dividable to } L,} \\ {\left[\frac{R}{L}\right] ; \text { if } R \text { is not dividable to } L,}\end{array}\right.$

where $N$ is the optimal size of the component; $d$ is the real discount rate per annum, which is a function of the nominal discount rate and the nominal inflation rate; $R$ is the projected lifetime of the MG system; and $L$ is the lifetime of each component in years. In this study, $d$ and $R$ are assumed as $6 \%$ and 20 years, respectively.

In addition, the upper bounds on the non-negative design variables of the problem at hand are set as follows:

$N_{P V} \leq 3,000 ; N_{W T 1} \leq 20 ; \quad N_{W T 2} \leq 20 ; \quad N_{M H} \leq 20 ; \quad N_{B} \leq 700 ;$

$N_{F C} \leq 700 ; N_{E} \leq 3,000 ; N_{H T} \leq 2,000 ; N_{S} \leq 20 ; N_{S C} \leq 25,000 ;$

$N_{I} \leq 700$

As mentioned earlier, the optimized variables must adhere to the reliability and operational constraints, which ensure the continuous availability of energy supply for residential electrical and hydrogen loads within the MG over its projected lifetime. These constraints can be summarized as follows.

As the most important constraint in the planning level of the devised method, the equivalent loss factor (ELF) reliability indicator for supplying the electrical and hydrogen loads, which can be measured using Eq. (24), must be lower than 0.01 [44].

$E L F=\frac{1}{T} \sum_{t=1}^{T} \frac{Q_{L}(t)+Q_{S}(t)}{P_{L}(t)+P_{S}(t)}$,

where $Q_{L}(t)$ and $Q_{S}(t)$ represent the value of the lost residential electrical and hydrogen loads at time step $t(\mathrm{kWh})$, respectively; while $T$ indicates the operational timeframe adopted within the optimal capacity planning strategy, i.e. $288 \mathrm{~h}$ according to the monthly-averaged daily (24-h) profiles for the climatic and demand data found on the corresponding one-year hourly data streams. It must be noted that such a model reduction technique, established on the appropriate compression of input data is inspired by the idea developed by Mavrotas et al. [45] to reduce the computational costs, whilst preserving the solution accuracy at an acceptable level.

There are two other constraints that must be met in the planning phase of the developed method. The first one, the constraint imposed by Eq. (25), guarantees that the amount of hydrogen stored in the tank at the end of the specified operational timeframe will be equal or exceed the initial tank level. The second is that the optimal combination of the sizes of the MG components must satisfy the constraint in Eq. (26) to ensure that the amount of energy stored in the SC bank at the beginning of the operational planning horizon is lower than its final state of charge.

$E_{H T}(288) \geq E_{H T}(0)$,

$E_{S C}(288) \geq E_{S C}(0)$.

As illustrated above, in order to relax the planning phase constraints, a semi-infinite penalty factor is utilized to incorporate them into the considered single-objective fitness function that is applied if any of the corresponding constraints (that are checked after operating the MG using the generated candidate solutions at each iteration) are violated. It must also be noted that it is assumed that the hydrogen tank and SC modules are half-full charged at the beginning of the simulation.

The optimization procedure is also subject to some constraints on the operation of the MG system. In this regard, according to the constraint imposed by Eq. (27), the energy storage capacity of the tank should lie in a certain range at each time step so as to model the facts that the mass of hydrogen stored in the tank cannot exceed its nominal capacity and a small fraction of the hydrogen cannot be released due to some pressure-drop concerns.

$E_{H T, \min } \leq E_{H T}(t) \leq E_{H T, \max }$,

where $E_{H T, \min }$ and $E_{H T, \max }$ are the minimum and maximum permissible storage capacities of the tank, respectively. In this paper, $E_{H T, \min }$ is set as $5 \%$ of $E_{H T, \max }$, as suggested by Kashefi-Kaviani et al. [46]. Furthermore, $E_{H T, \max }$ represents the optimal capacity of the tank (which could be calculated by converting the hydrogen mass to its energy content using Eq. (6)), which is determined at each iteration of the optimization protocol.

In addition, the amount of energy stored in the SC bank at each time step is constrained via Eq. (28) to be in the allowable range.

$E_{S C, \min } \leq E_{S C}(t) \leq E_{S C, \max }$

where $E_{S C, \min }$ and $E_{S C, \max }$ are the minimum and maximum permissible storage capacities of the SC bank that are expressed by the following equations [38]:

$E_{S C, \min }=\left(0.5 \times N_{S C} \times U_{S C, \min }^{2}\right) /\left(3.6 \times 10^{6}\right)$,

$E_{S C, \max }=\left(0.5 \times N_{S C} \times U_{S C, \max }^{2}\right) /\left(3.6 \times 10^{6}\right)$,

where $N_{S C}$ represents the optimal number of SC modules identified at each iteration of the optimization protocol; $U_{S C \text {, min }}$ and $U_{S C, \max }$ denote the minimum and maximum permissible voltage levels of the SC modules, respectively; while the numerical value of $3.6 \times 10^{6}$ converts the unit of measurement from $\mathrm{J}$ to $\mathrm{kWh}$.

In order to accommodate the operational constraints in our model, we have defined the upper and lower bounds associated with relevant variables to lie within pre-specified ranges.

Moreover, an overview of the proposed generic framework to assess the performances of the considered MHOAs using the devised hydrogen-based test-case MG is available as Supplementary Material accompanying the paper (Additional File 3: Fig. S1).

\section{Results and discussion}

The conceptualized MG, shown in Fig. 1, is used to examine and validate the proposed approach by analyzing the impact of the employed MHOAs on the projected total NPC of the MG, as well as the rate of convergence. The simulations were conducted on the Intel ${ }^{\otimes}$ Core $^{\mathrm{TM}}$ i7$4770 \mathrm{CPU}, 3.40 \mathrm{GHz}$ using the MATLAB software.

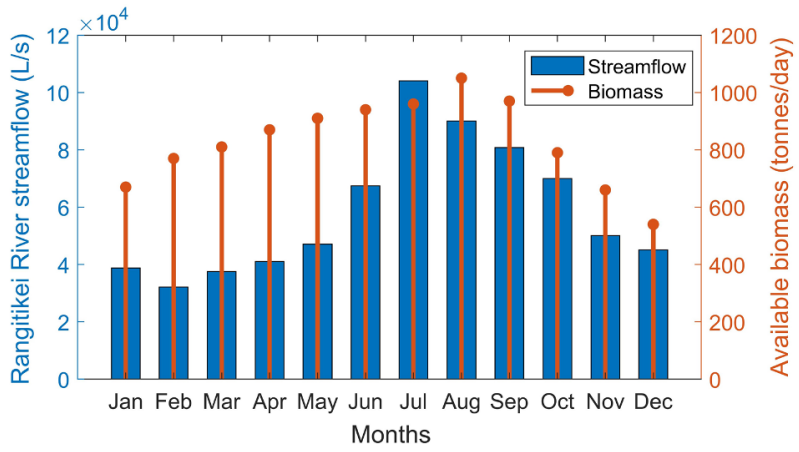

Fig. 3. Monthly mean profiles for the streamflow and available wet biomass. 


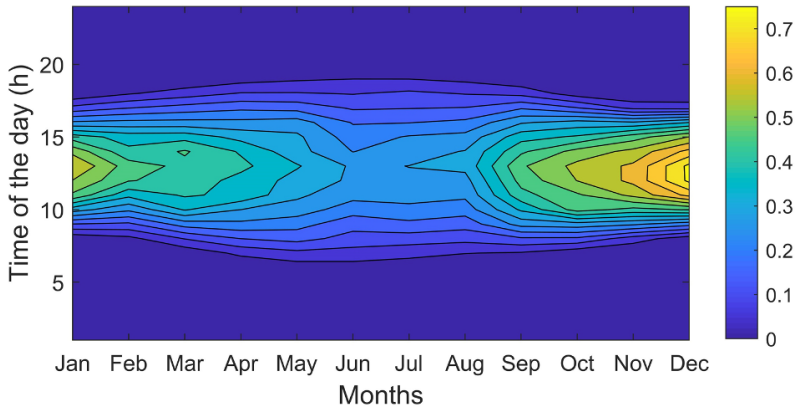

Fig. 4. Contour plot of the monthly-averaged 24-h profile for the solar irradiance $\left(\mathrm{kW} / \mathrm{m}^{2}\right)$.

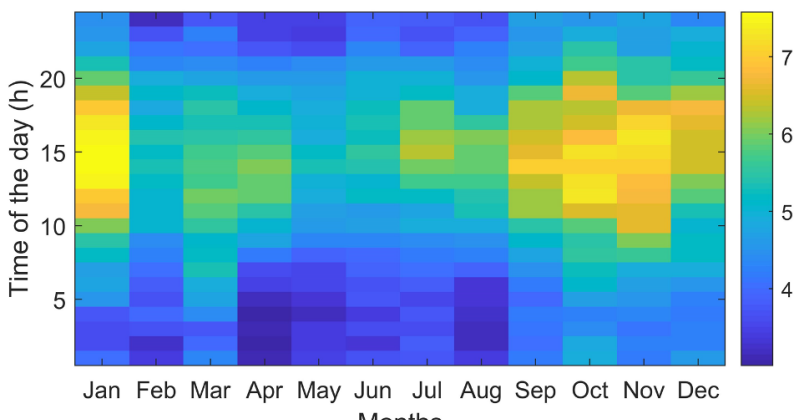

Fig. 5. Heatmap plot of the monthly-averaged 24-h profile for the wind speed $(\mathrm{m} / \mathrm{s})$.

\subsection{Input data}

A case study was undertaken to optimally design the notional hydrogen-based MG proposed in this paper for a rural community in the Feilding area, New Zealand (latitude $40.2253^{\circ} \mathrm{N}$, longitude $\left.175.5675^{\circ} \mathrm{E}\right)$. The number of the target population for which the MG system is conceptually developed is 350 .

The 15 years (2003-2017) environmental data (with 1-h resolution) recorded for the considered site were acquired from the New Zealand's National Climate Database [47]. The forecasted monthly mean streamflow for the Rangitikei River, located at the case study site, and the monthly mean variations of the wet biomass predicted to be available at the site are presented in Fig. 3. The forecasted monthlyaveraged daily profiles for the solar irradiance and wind speed (measured at the height of $48 \mathrm{~m}$ ), extracted from the respective one-year hourly data streams are shown in Figs. 4 and 5, respectively. Notice that the one-year hourly solar irradiance and wind speed data streams are determined by averaging the respective historical records with an hourly resolution. Furthermore, note that the collected wind speed data are normalized to the heights of 27 and $38 \mathrm{~m}$ (in compliance with the hub heights of FL30 and FL100 WTs), using Eq. (2).

The monthly mean 24-h profile for the hourly residential loads on the MG over a year, forecasted and further scaled with respect to the New Zealand GREEN grid household electricity demand study [48] is shown in Fig. 6, which has a high proportion of electric space heating load during wintertime. For the hydrogen loads (hydrogen power required by the station to serve the hydrogen fuel cell trucks and tractors), first, it is assumed that five $\mathrm{NH} 2$ fuel cell tractors and five Hyundai fuel cell trucks have to be integrated into the system. The hydrogen load profile is then forecasted assuming that the aforementioned vehicles are refuelled in the early morning hours between 0 and 5 am on weekdays, when the residential electrical load is low so as to fill up the valley in the overall daily energy demand profile of the MG. Also, it is assumed that the vehicles are refuelled once per week on average. Hence, a constant load of nearly $6.65 \mathrm{~kg} \mathrm{H}_{2} / \mathrm{h}$ is imposed on the MG system every day between 0 and 5 am on weekdays.

The technical and economic characteristics of the components of the conceptualized hydrogen-based MG are shown in Table 1 $[33,34,36,38,40,46,49-55]$. Throughout this paper, all the costs and prices are expressed in US dollars (\$). Where necessary, they have been converted to US dollars using the average 2018 currency exchange rates, as in the case of local energy prices [56].

\subsection{Performance comparison of the adopted MHOAs}

In order to carry out a fair comparison between the investigated optimization techniques, the maximum number of iterations (generations) and the number of their individuals/particles are kept constant for all the examined algorithms, which are considered to be 300 and 45, respectively. Other specific parameters of the evaluated algorithms are adjusted according to the values recommended by their developers, as indicated in Table 2 [22-30]. Notice that no parameter adjustment is required for the SSA, the ALO, and the GWO algorithms, since their parameters are adjusted adaptively over the course of iterations. In addition, as it is generally accepted that 30 runs are adequate for comparing the performances of different MHOAs [57], the optimization procedure is repeated for 30 independent runs for each metaheuristic algorithm. The calculated optimal size (capacity/quantity) and type (where applicable) of the equipment incorporated in the MG structure, as well as the total NPC of the MG system are given in Table $3-$ which are determined by the application of the considered optimization algorithms and rounded up to the nearest integer in the case of continuous variables (except for the hydrogen station's capacity, which is rounded up to the second decimal place due to its prohibitive costs). Note that the results reported in Table 3 refer to the best performance of the algorithms out of 30 trials. For better clarity of the best results obtained out of 30 runs using the selected MHOAs, the calculated sizes of the MG components are also compared in Fig. 7 on a radar (spider) graph in log scales. Interestingly, all the algorithms agreed upon the sizes of WTs and MHPPs, whose NPCs account for a large proportion of the total NPC of the MG, as well as upon the size of the hydrogen refuelling station.

Furthermore, Fig. 8 presents the comparative convergence curves of the applied optimization methods for the trials, where the algorithms have shown their best performances in terms of nearing the global optima. As can be seen from the figure, the PSO has the fastest convergence rate among all the applied algorithms and approximates the global optimal solution in very few iterations. The figure also reveals that the GWO (i.e. the third-best algorithm) has a very similar convergence trend to that of the PSO in the initial iterations, but it converges much slower than the PSO; the convergence speed of the GA is

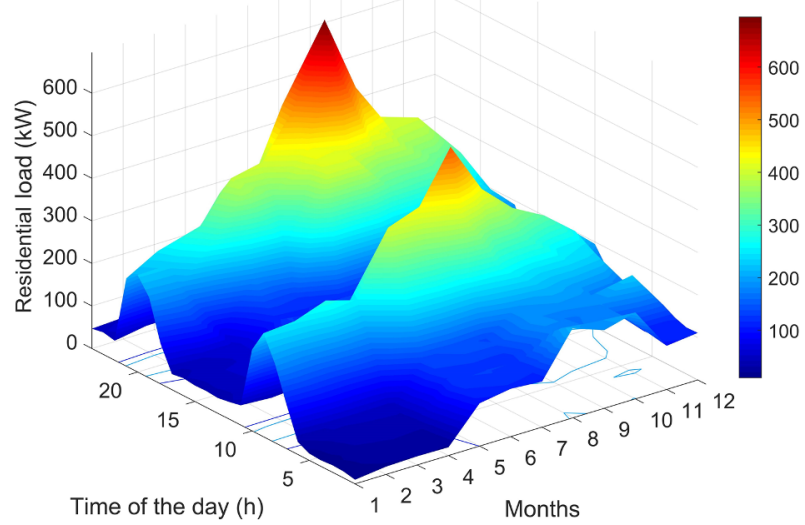

Fig. 6. 3D plot of the monthly mean diurnal variations of residential electrical load power demand. 
Table 1

Techno-economic specifications of the MG components.

\begin{tabular}{|c|c|c|c|c|c|c|}
\hline Component & Product model & Capital cost & Replacement cost & $\mathrm{O} \& \mathrm{M}$ cost & Lifetime [yr] & Reference(s) \\
\hline PV panel & CS6U-325P & $\$ 700 /$ unit & $\$ 500 /$ unit & $\$ 14 /$ unit/yr & 20 & [33] \\
\hline \multirow[t]{2}{*}{ WT } & FL30 & $\$ 83,000 /$ unit & $\$ 75,000 /$ unit & $\$ 3,100 /$ unit/yr & 20 & {$[34,49]$} \\
\hline & FL100 & $\$ 220,000 /$ unit & $\$ 200,000 /$ unit & $\$ 8,600 /$ unit/yr & 20 & \\
\hline MHPP & FJ-7A & $\$ 55,000 /$ unit & $\$ 50,000 /$ unit & $\$ 1,900 /$ unit/yr & 25 & {$[36]$} \\
\hline SC & MAXWELL EDLC & $\$ 32 /$ unit & \$32/unit & $\$ 0.64 /$ unit/yr & 10 & {$[38,50]$} \\
\hline Biopower plant & Generic & $\$ 1,150 / \mathrm{kW}$ & $\$ 1,000 / \mathrm{kW}$ & $\$ 30 / \mathrm{kW} / \mathrm{yr}$ & 20 & {$[40]$} \\
\hline Electrolyser & Generic & $\$ 800 / \mathrm{kW}$ & $\$ 800 / \mathrm{kW}$ & $\$ 16 / \mathrm{kW} / \mathrm{yr}$ & 15 & {$[46,51]$} \\
\hline $\mathrm{H}_{2} \operatorname{tank}$ & Generic & $\$ 470 / \mathrm{kg}$ & $\$ 470 / \mathrm{kg}$ & $\$ 1 / \mathrm{kg} / \mathrm{yr}$ & 20 & {$[46]$} \\
\hline Fuel cell & Generic & $\$ 2,400 / \mathrm{kW}$ & $\$ 2,400 / \mathrm{kW}$ & $\$ 120 / \mathrm{kW} / \mathrm{yr}$ & 5 & {$[46,51]$} \\
\hline $\mathrm{H}_{2}$ station & Generic & $\$ 6,000 / \mathrm{kg} \mathrm{H}_{2} / \mathrm{h}$ & $\$ 5,000 / \mathrm{kg} \mathrm{H}_{2} / \mathrm{h}$ & $\$ 180 / \mathrm{kg} \mathrm{H}_{2} / \mathrm{h} / \mathrm{yr}$ & 20 & {$[52,53,54]$} \\
\hline Inverter & Generic & $\$ 350 / \mathrm{kW}$ & $\$ 350 / \mathrm{kW}$ & $\$ 7 / \mathrm{kW} / \mathrm{yr}$ & 15 & {$[33,55]$} \\
\hline
\end{tabular}

Table 2

Parameter settings for the metaheuristics under comparison.

\begin{tabular}{lll}
\hline Algorithm & Parameter settings* & Reference(s) \\
\hline GA & $P_{\text {cross }}=0.1, P_{m u t}=0.9$ & {$[28,29]$} \\
PSO & $c_{1}=2, c_{2}=2, \omega=0.7$ & {$[30]$} \\
MFOA & $b=1$ & {$[22]$} \\
DA & $s=0.1, a=0.1, c=0.7, f=1, e=1, \omega=0.7$ & {$[23]$} \\
GOA & $l=1.5, f=0.5$ & {$[27]$} \\
SSA & Parameters are adjusted adaptively (dynamic & {$[24]$} \\
& adjustment) & {$[25]$} \\
ALO & Parameters are adjusted adaptively (dynamic & \\
& adjustment) & {$[26]$} \\
GWO & Parameters are adjusted adaptively (dynamic & \\
& adjustment) &
\end{tabular}

* A detailed description of the parameters of the algorithms is provided as Supplementary Material (Additional File 1: An overview of the selected metaheuristic optimization algorithms).

competitive with that of the GWO; the MFOA shows a strong capability of searching the design space in the last iterations, when the other algorithms have got stuck into the local optimum points (which underlines its strong exploitation capability, i.e. the procedure aiming at better approximating the global optima by searching around the achieved solutions in the all-around exploration phase), defeating the GA in the 232nd iteration. Finally, the DA, the SSA, the ALO, and the GOA not only have trapped into the local optima solutions prematurely, but also had the characteristics of slow convergence.

Since making deductions regarding the ranking of the employed algorithms based only on the best-case results might influence the validity of ratings, inspired by the idea proposed by Maleki and Pourfayaz [4], a comparison framework is used in this study that ranks the performance of the studied algorithms by averaging the following four metrics: the best-case results (Best), the worst-case results (Worst), the mean results (Mean), and the median values (Median) of the total NPC results over all 30 independent trials. Note that we have modified the average-based decision-making framework put forward by Maleki and Pourfayaz [4] through replacing the standard deviation metric by the median metric in order to: (i) retain the order of metrics at the same

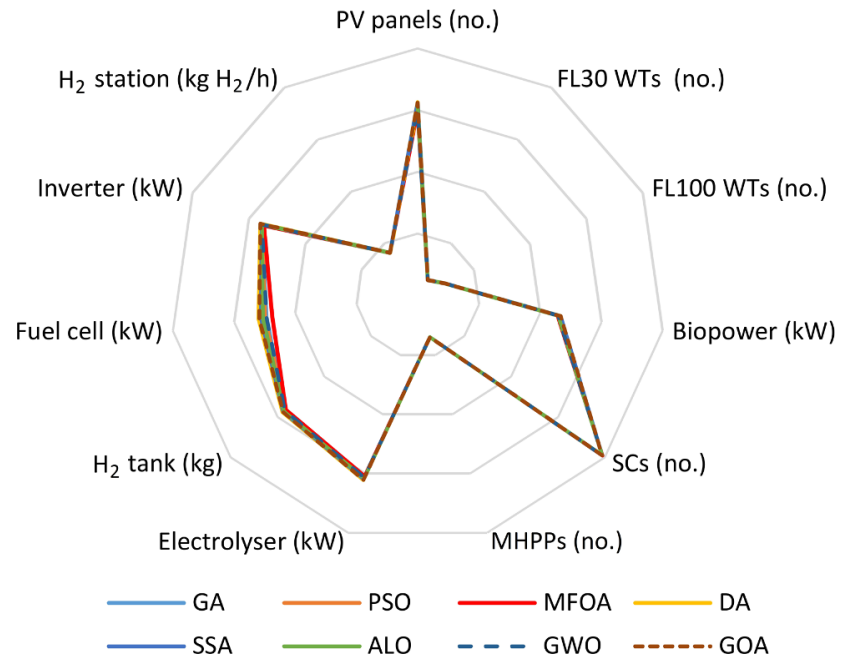

Fig. 7. Radar graph of the best combination of the sizes of MG components for the eight MHOAs under evaluation.

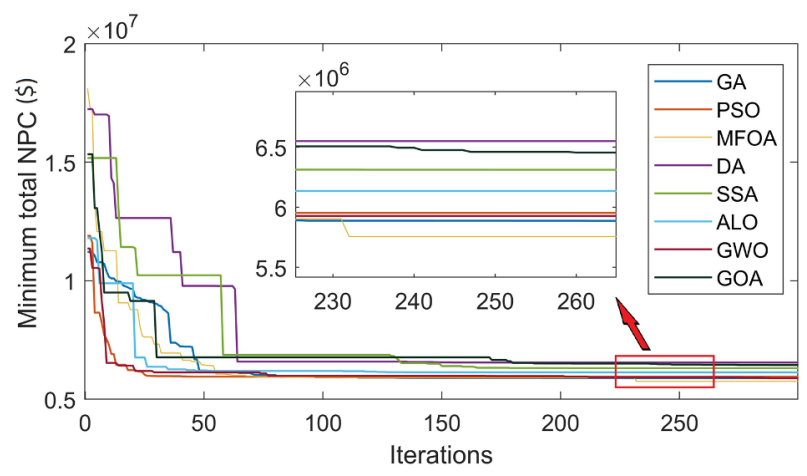

Fig. 8. Convergence curves of the best-case behaviours of the eight optimization algorithms over 30 runs.

Table 3

Comparative results of the best-case performances of the adopted algorithms over 30 runs.

\begin{tabular}{|c|c|c|c|c|c|c|c|c|c|c|c|c|}
\hline Alg. & $\begin{array}{l}\text { PV panels } \\
\text { (no.) }\end{array}$ & $\begin{array}{l}\text { FL30 WTs } \\
\text { (no.) }\end{array}$ & $\begin{array}{l}\text { FL100 WTs } \\
\text { (no.) }\end{array}$ & $\begin{array}{l}\text { Bio-power } \\
(\mathrm{kW})\end{array}$ & SCs (no.) & MHPPs (no.) & $\begin{array}{l}\text { Elec. } \\
(\mathrm{kW})\end{array}$ & $\begin{array}{l}\mathrm{H}_{2} \text { tank } \\
(\mathrm{kg})\end{array}$ & $\begin{array}{l}\text { Fuel cell } \\
(\mathrm{kW})\end{array}$ & Inv. (kW) & $\begin{array}{l}\mathrm{H}_{2} \text { station }(\mathrm{kg} \\
\left.\mathrm{H}_{2} / \mathrm{h}\right)\end{array}$ & Total NPC (\$) \\
\hline GA & 1058 & 2 & 3 & 195 & 8961 & 5 & 1174 & 702 & 294 & 588 & 6.65 & $5,904,819$ \\
\hline PSO & 1086 & 2 & 3 & 197 & 8987 & 5 & 1181 & 708 & 311 & 588 & 6.65 & $5,969,038$ \\
\hline MFOA & 1009 & 2 & 3 & 191 & 9003 & 5 & 1110 & 663 & 239 & 541 & 6.65 & $5,780,909$ \\
\hline $\mathrm{DA}$ & 1351 & 2 & 3 & 213 & 8744 & 5 & 1289 & 769 & 401 & 630 & 6.65 & $6,537,412$ \\
\hline SSA & 1301 & 2 & 3 & 219 & 8820 & 5 & 1234 & 754 & 364 & 593 & 6.65 & $6,310,277$ \\
\hline ALO & 1128 & 2 & 3 & 198 & 8839 & 5 & 1206 & 733 & 338 & 587 & 6.65 & $6,142,238$ \\
\hline GWO & 1055 & 2 & 3 & 196 & 8955 & 5 & 1173 & 701 & 295 & 587 & 6.65 & $5,907,284$ \\
\hline GOA & 1327 & 2 & 3 & 220 & 8732 & 5 & 1279 & 755 & 387 & 624 & 6.65 & $6,436,362$ \\
\hline
\end{tabular}


Table 4

Statistical performance comparison of the investigated algorithms in terms of minimizing the total NPC (\$).

\begin{tabular}{|c|c|c|c|c|c|c|c|c|}
\hline Metrics & GA & PSO & MFOA & DA & SSA & ALO & GWO & GOA \\
\hline Best & $5,904,819$ & $5,969,038$ & $5,780,909$ & $6,537,412$ & $6,310,277$ & $6,142,238$ & $5,907,284$ & $6,436,362$ \\
\hline Worst & $5,932,667$ & $6,002,465$ & $5,798,252$ & $7,394,813$ & $7,008,684$ & $6,688,897$ & $5,926,095$ & $6,950,798$ \\
\hline Mean & $5,906,052$ & $5,973,664$ & $5,781,106$ & $6,706,548$ & $6,324,951$ & $6,149,367$ & $5,909,225$ & $6,449,559$ \\
\hline Median & $5,904,819$ & $5,969,038$ & $5,780,909$ & $7,062,930$ & $6,345,074$ & $6,150,802$ & $5,907,284$ & $6,753,924$ \\
\hline Avg. & $5,912,089$ & $5,978,551$ & $5,785,294$ & $6,925,426$ & $6,497,247$ & $6,282,826$ & $5,912,472$ & $6,647,661$ \\
\hline Rank & 2 & 4 & 1 & 8 & 6 & 5 & 3 & 7 \\
\hline
\end{tabular}

level, thereby precluding the need for assigning appropriate weighting factors to the metrics of the comparison framework, and (ii) tacitly incorporate the number of hits to the optimum solution (per 30 trials) into the decision-making process. It must also be noted that since MGs are usually designed for a projected lifespan of 20-30 years, the solution quality is often selected by the MG designers as the decisive criterion rather than the computational cost, when making decisions regarding the superiority of an MHOA, unless it is computationally intractable, which has not been the case here. Hence, convergence rates of the investigated algorithms have not been incorporated into the decision-making procedure employed to compare the performances of the selected metaheuristics in the context of the MG planning and design.

Table 4 ranks the performance of the analyzed algorithms in terms of both the solution optimality and stability. The scoring process is carried out by defining a composite indicator ( $A v g$.), which combines the pre-defined Best, Worst, Mean, and Median metrics by averaging them. The table is revealing in several ways. Firstly, it highlights that the MFOA outperforms all the other algorithms in terms of approximating the global optima for the considered optimal MG design problem. Particularly, it outperforms the GA (i.e. the second-best algorithm) in minimizing the total NPC of the MG by nearly $2.1 \%$ based on the overall performance indicator (resulting in a cost saving of $\$ 123,910$ based on their best-case performances). It can be interpreted from Fig. 7 that a major reduction in the optimized capacity of the fuel cell compared to the other algorithms, is the overriding reason for the MFOA's supreme performance. Secondly, it shows that the GWO obtains very close results to those of the GA (with a discrepancy of less than $0.01 \%$ in $A v g$. indicator). Thirdly, it proves that the PSO gains the fourth position; approximating the global minimum of the total NPC almost $3.2 \%$ higher than that determined by the MFOA (i.e. the superior algorithm in terms of solution accuracy) with respect to the Avg. indicator. The relatively satisfactory performances of the GA and the PSO, compared with the DA, the SSA, the ALO, and the GOA (which are newly developed MHOAs), justify their extensive use in this research area. This brings us to the fourth observation: the optimum results obtained by the DA, the SSA, the ALO, and the GOA are rather disappointing. This can be justified by the NFL theorem, according to which it can be deduced that the recently-developed DA, SSA, ALO, and GOA techniques are not suitable for solving the optimal MG planning problems. Finally, it can be indirectly inferred from the Median results of the table that at least 16 trials of the MFOA, the GA, the GWO, and the PSO algorithms have hit their corresponding best solutions, indicating their high robustness against the initial random points, which reaffirms their suitability for the MG sizing applications. These findings collectively implicate that the MFOA can be selected as the best algorithm among those investigated in this study, as it is able to effectively search near the global optima and provide a solution, which is relatively better than those obtained by the GA, the PSO, and the GWO, while being by far, better than those obtained by the other evaluated techniques (i.e. the DA, the SSA, the ALO, and the GOA).

\subsubsection{Comparison of the performance of the MFOA with its improved variants}

In view of the continuously evolving landscape of the swarm-based metaheuristic optimization algorithms, this sub-section seeks to investigate the performance of the modified variants of the MFOA, when applied to the optimal equipment capacity planning problem of the MG system laid out in Section 2. To this end, seven modified versions of the MFOA were identified and applied to the problem at hand, namely (i) the improved MFOA (IMFOA) [58], (ii) the moth swarm algorithm (MSA) [59], (iii) the hybrid GA-MSA (HGA-MSA) [60], (iv) the timeconstrained GA-MFOA (TGA-MFOA) [61], (v) the hybrid simulated annealing algorithm-MFOA (HSAA-MFOA) [62], (vi) the hybrid water cycle-MFOA (HWC-MFOA) [63], and (vii) the hybrid SSA-MFOA (HSSA-MFOA) [64]. These algorithms have been confirmed as superior to the original MFOA using either a standard set of benchmark (test) functions and/or test-case engineering optimization problem(s). The delivered outperformance of the aforementioned algorithms over the basic MFOA has emanated from (1) the hybridization of the MFOA with the algorithms having a better exploration capability, or (2) adding features such as random-walk trajectories (e.g. Lévy flight) to achieve a better trade-off between the exploration and exploitation phases of the algorithm. Also, all the parameters of the investigated algorithms were tuned as suggested by their developers. Table 5 statistically compares the performance of the MFOA with those of its enhanced variants in terms of solution accuracy. From the table, two key observations could be made: (1) there is no guarantee that an improved variant of a metaheuristic algorithm outperforms its original version in every application, a result consistent with the NFL theorem - which gives credence to the idea that the efficiency of the metaheuristics is highly contextdependent; and (2) the contribution of the modifications carried out to date to the MFOA to the improvements in solution quality is found to be in the $0.11-0.37 \%$ range (with respect to the best-case solutions), if any - which is deemed not to be significant in the context of the long-term MG investment planning.

As illustrated above, the computational budget for the long-term infrastructure planning problem of MGs is very large and the

Table 5

Statistics-based performance comparison of the MFOA with its improved variants in terms of minimizing the total NPC (\$).

\begin{tabular}{|c|c|c|c|c|c|c|c|c|}
\hline Metrics & IMFOA & MSA & HGA-MSA & TGA-MFOA & HSAA-MFOA & HWC-MFOA & HSSA-MFOA & MFOA \\
\hline Best & $5,762,988$ & $5,774,550$ & $5,785,594$ & $5,783,030$ & $5,791,893$ & $5,768,191$ & $5,759,520$ & $5,780,909$ \\
\hline Worst & $5,780,304$ & $5,788,627$ & $5,799,368$ & $5,797,296$ & $5,816,418$ & $5,789,037$ & $5,773,681$ & $5,798,252$ \\
\hline Mean & $5,763,691$ & $5,776,394$ & $5,786,790$ & $5,783,944$ & $5,793,026$ & $5,768,957$ & $5,760,007$ & $5,781,106$ \\
\hline Median & $5,762,988$ & $5,774,550$ & $5,785,594$ & $5,783,030$ & $5,791,893$ & $5,768,191$ & $5,759,520$ & $5,780,909$ \\
\hline Avg. & $5,767,492$ & $5,778,530$ & $5,789,337$ & $5,786,825$ & $5,798,308$ & $5,773,594$ & $5,763,182$ & $5,785,294$ \\
\hline Rank & 2 & 4 & 7 & 6 & 8 & 3 & 1 & 5 \\
\hline
\end{tabular}




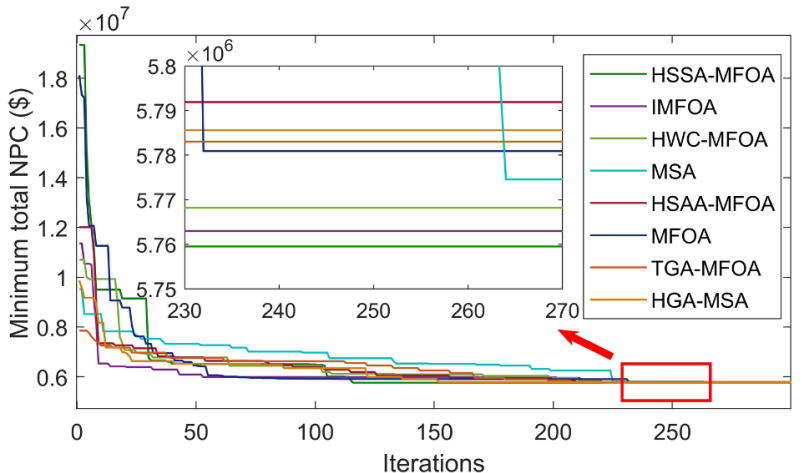

Fig. 9. Convergence curves of the best-case performance of the MFOA and its improved variants after 30 trials.

computational burden is not often considered as the determining factor, while comparing the metaheuristics' efficiencies in the context of the long-term MG's infrastructure planning. Nonetheless, since all the aforementioned variants of the MFOA seek to address the explorationexploitation dilemma by improving the balance between these two stages, they are also evaluated in terms of computational intensity. Accordingly, Fig. 9 compares the convergence rate of the MFOA with those of its state-of-the-art variants in their best performance throughout 30 independent simulation runs. Key remarks from Fig. 9 can be summarized as follows: (i) the HSSA-MFOA not only outperforms the MFOA and its other variants in terms of the solution quality (albeit by a small margin), but also converges much faster than them (in 116 epochs); hence it seems to offer the best compromise between the exploration and exploitation phases; (ii) the performance of the IMFOA, the HWC-MFOA, and the TGA-MFOA is superior to the MFOA (again, only by a small margin), whilst having comparable computational requirements to that of the MFOA; (iii) the MSA delivers a slightly better performance than the MFOA, but at the expense of higher computational overheads, (iv) the poor performance of the HGA-MSA could be ascribed to its failure to avoid search stagnation, and (v) although the computational burden of the HSAA-MFOA is comparable to the MFOA, it suffers from the premature convergence problem.

\subsection{Economic and energetic analyses of the system}

This section presents the economic and energetic evaluations for the optimal combination of the sizes of the MG components, approximated by the MFOA, whose superior efficiency over the other examined MHOAs has been demonstrated in the previous sub-section. Accordingly, a breakdown of the total NPC of the MG, as well as the energy flow analysis of the MG for a one-year operational timeframe, are detailed in the following sub-sections. Note that all the analyses are carried out based on the best-case performance of the MFOA.

\subsubsection{Total NPC breakdown}

As stated earlier, the total NPC of the MG is calculated to be $\$ 5,780,909$. The capital, replacement, and O\&M costs of the MG account for nearly $68 \%, 29 \%$, and $3 \%$ of the total NPC, respectively. Furthermore, the total salvage value of the investment plan at the end of the 20th year, stemming from the difference between the project lifetime and lifetimes of MHPPs, the electrolyser, and the inverter, is calculated to be $\$ 782,901$. The donut chart in Fig. 10 breaks down the total NPC of the system by components. As illustrated in the figure, the NPCs of FL30 WTs, FL100 WTs, PV panels, MHPPs, the electrolyser, the hydrogen tank, the fuel cell, the hydrogen filling station, SCs, the biopower plant, and the inverter have approximately contributed to almost $4 \%, 14 \%, 16 \%, 5 \%, 20 \%, 6 \%, 12 \%$, less than $1 \%, 12 \%, 5 \%$, and $6 \%$ of the total NPC, respectively. The electrolyser, which plays a pivotal role in the proposed system by producing hydrogen for refuelling the fuel cell vehicles and backing up the intermittent renewable generation in the long-run, has occupied the largest share of the total NPC. By evaluating the relationships between the obtained sizes for the hydrogen sub-system's components, the optimization protocol's decision in utilizing the available renewable power during early morning hours in order to refuel the vehicles and not to utilize the hydrogen stored in the tank for this purpose (since the input flow of the hydrogen reservoir is found to be equal to its outflow to the station plus its charging flow between 0 and 5 am on workdays) has been identified as the responsible factor for the higher capacity of the electrolyzer - when proportionally compared to the sizes of the reservoir and fuel cell. In order to further uncover the cost elements of the system equipment, Fig. 11 shows the cash flow analysis of the conceptualized MG system for the considered case study site. As detailed in the figure, all the components incur O\&M costs; the electrolyser, the fuel cell, SCs, and the inverter incur replacement costs, among which, only the fuel cell's replacement cost is relatively much higher than its capital cost, which is due to the more than one fuel cell replacement over the project lifetime (i.e. three times); while MHPPs, the electrolyser, and the inverter are expected to return salvage values at the end of the project lifetime.

Moreover, by adapting the method proposed by Lotfi and Khodaei [65], the levelized cost of energy (LCOE) of the MG is calculated by dividing the total NPC of the MG by the total energy it supplies to customers during its life-cycle in the forms of electricity and hydrogen (i.e. defined as useful energy in this paper). The LCOE is then segregated into the levelized costs of electricity and hydrogen production, leveraging the fact that the costs associated with the components that have no role in supplying each energy form (e.g. the hydrogen station plays no role in supplying the electricity) should not be included in its levelized cost formulation, which are calculated to be $\$ 0.09 / \mathrm{kWh}$ and $\$ 4.61 / \mathrm{kg}$, respectively. Currently, the electricity tariff in New Zealand is between $\$ 0.11 / \mathrm{kWh}$ and $\$ 0.16 / \mathrm{kWh}$ for residential consumers depending on the amount of electricity consumption, selected power supply company, and greenness of power (note that the prices are reported in US dollars) [66]. The calculated levelized cost of electricity for the MG is $30 \%$ lower than the average residential electricity tariffs in New Zealand. In addition, the most up to date estimated cost of sustainable hydrogen production in small-scale in New Zealand is as high as $\$ 9.43 / \mathrm{kg}$, which is more than two times the hydrogen price estimated in this project [67]. That is, according to the projected useful lifetime of the MG (i.e. 20 years), the circa $2 \%$ increase in electricity prices in New Zealand per annum, the environmental benefits of the conceptualized $100 \%$ renewable energy system, its substantial contribution to improving the resilience of

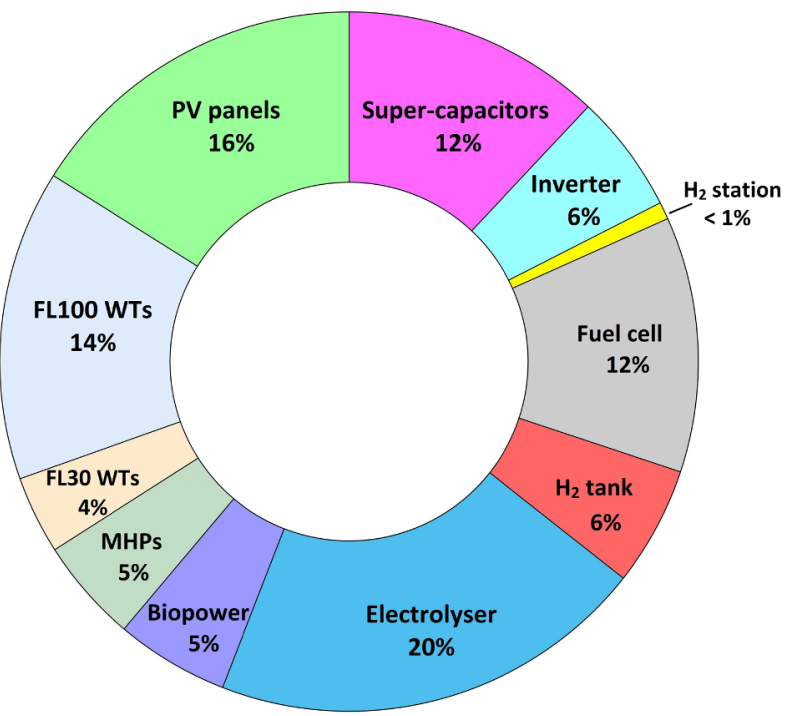

Fig. 10. Breakdown of the best total NPC obtained using the MFOA out of 30 runs. 


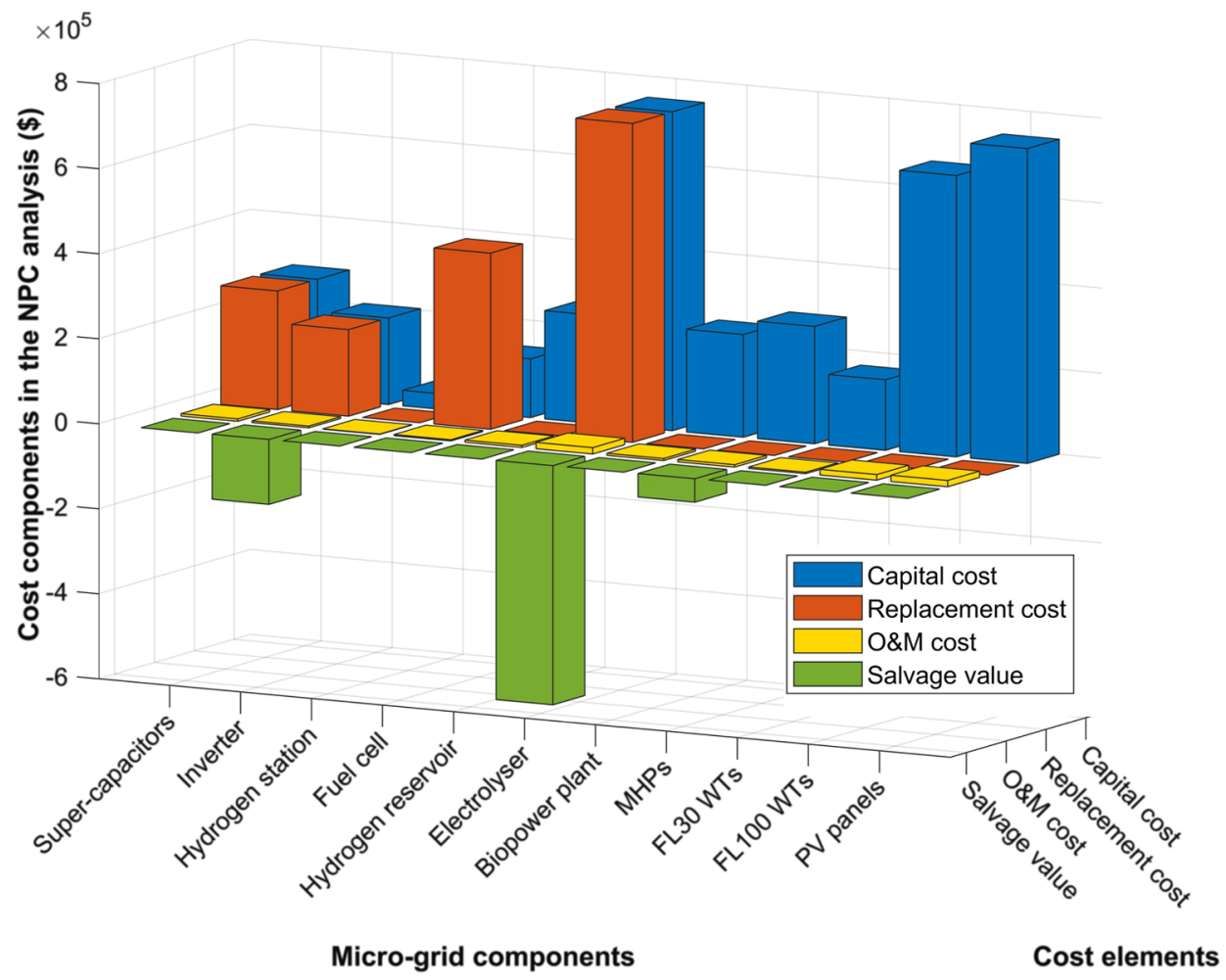

Fig. 11. Cash flow breakdown by micro-grid components and cost categories.

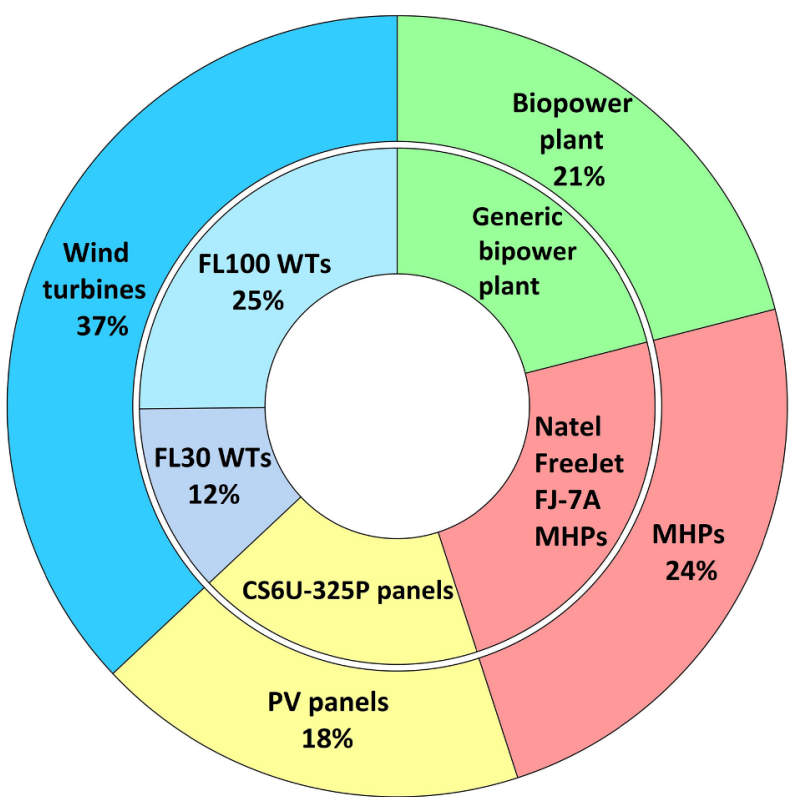

Fig. 12. Contribution of each renewable energy generation technology to the total produced energy.

remote communities through making them energy self-sufficient, implementing an efficient wet biomass waste stream management programme, as well as laying the foundations for the integration of hydrogen fuel cell tractors and trucks that support the cost-effective and affordable movement towards the realization of the sustainable agriculture goals, the economic viability of realizing the proposed MG for the considered case study site is ensured.

\subsubsection{Energy flow}

The MG energy flow analysis for a year-long operation of the system (with 1-h resolution and without reducing the operational time frame to $288 \mathrm{~h}$ in accordance with the data compression-directed model reduction strategy) using the optimal combination of the sizes of the components is carried out in this sub-section. The results of the energy flow analysis on the generation side are presented in Fig. 12. From the donut chart, one can note that almost $37 \%$ of the total energy generated within the MG is contributed by WTs, of which the FL100 WTs have had a share of around $68 \%$, with the FL30 WTs generating about $32 \%$ of the wind power within the MG. Also, it can be seen in the figure that the year-round energy production from PV panels, MHPPs, and the biopower plant have taken up roughly $18 \%, 24 \%$, and $21 \%$ of the total energy generated within the MG, respectively. On the other hand, Fig. 13 shows the contribution of various energy consumption elements to the total energy consumption within the MG. As shown in the donut chart in Fig. 13, at the first stage, the amount of consumed energy can be classified into useful and lost energy. Accordingly, almost $68 \%$ of the total renewable power generated within the MG is used for supplying the electrical and hydrogen loads, while $32 \%$ of the generated power is wasted due to the non-ideal characteristics of the components (i.e. the considered power/energy conversion efficiency ratings) or the energy storage limits. The useful power can then be further classified into the electrical power consumed by residential loads and hydrogen power delivered to the station to refuel the considered hydrogen-powered vehicles. The former contributes to approximately $91 \%$ of the total energy provided, while the latter is only responsible for circa $9 \%$ of the total useful energy consumption within the MG. Moreover, as it can be seen in the pie chart in Fig. 13, roughly $63 \%$ of the total lost energy is dumped as excess energy by circulating through the DC dump load (due to the lack of demand and/or storage capacity in the determined optimal solution set for the sizes of the components), while almost $19 \%$, $9 \%, 7 \%$, and $2 \%$ of the lost energy are respectively used to cater for the hydrogen sub-system (including the electrolyser, the hydrogen reservoir, and the fuel cell), the inverter, SCs, and the station losses. In addition, the energy flow analysis implies that the optimal planning and design of the conceptualized MG has led to the diversification of the RESs through an optimal quota allocation for the solar PV, wind, hydro, 


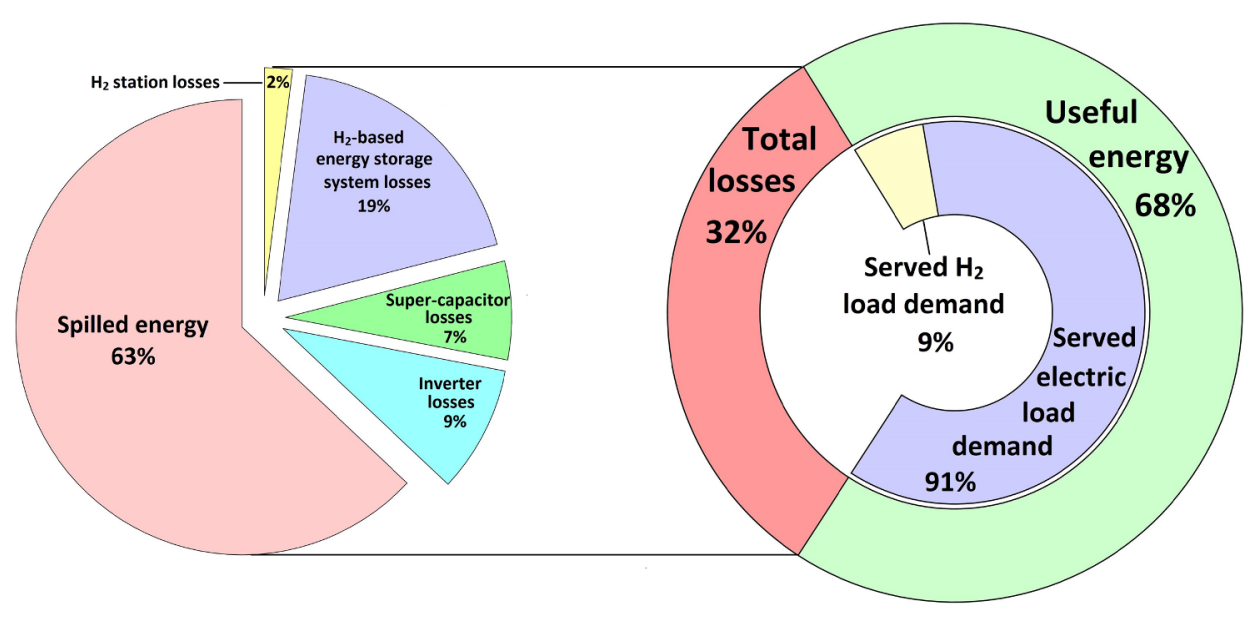

Fig. 13. Contribution of different energy consumption components to the overall energy consumption.

and bio resources; exploiting their complementary characteristics for power generation in short- and long-term horizons, thereby effectively ensuring the long-run sustainability and resilience of energy supply.

The ELF indicator for supplying the electrical and hydrogen loads, when operating the MG in the year-long operational timeframe, is determined to be $1.4 \%$. This result verifies the validity of the reduced model for operating the system within the optimization process. The reason is that the determined optimal combination of the MG components' sizes (with employing the model reduction technique to compress the operational timeframe) has resulted in an error of only $0.4 \%$ in the constrained level of the ELF index, when applied to the year-long operational analysis (without adopting the model reduction technique) of the proposed system, which is deemed acceptable. Furthermore, for better visualization of the unmet electrical and hydrogen loads, the system is first operated with a reduced model - where the operational time frame is considered to be $288 \mathrm{~h}$. Then, the unmet electrical and hydrogen load demands at each time step of the MG operation are calculated and aggregated. It is to be noted that the optimization protocol has a certain total unmet load budget, which could be spent unrestrictedly over the considered operational timeframe. The budget is in compliance with the imposed reliability constraint of $E L F \leq 0.01$. The monthly mean daily profile for the aggregate unmet electrical and hydrogen loads is shown in Fig. 14. In the figure, the unmet load power between 0 and 5 am is totally related to the loss of hydrogen load because this is the only time window scheduled for the refuelling of the fuel cell vehicles, at which there is a very light residential electrical load on the smart MG system. It is interesting to note that although there is adequate generation capacity to meet the hydrogen load, the optimization protocol has decided not to supply the station at some time steps to store more energy in the hydrogen reservoir to help manage the peak electricity demand more efficiently - thus furnishing a more intelligent asset-management operational strategy. Also note that the optimization protocol spends the entire allocated budget for load interruption, making it capable of avoiding the equipment capacity solution sets containing extra generation capacity only to satisfy the peak load power (which could be interpreted as peaker plants in conventional power systems).

\subsection{Model validation}

In order to further validate the economic viability of the project to be implemented in the considered case study site, we first calculate the dynamic payback period (DPP) of the proposed system. Then, we compare the total NPC of the conceptualized hydrogen-based MG with that of an identical MG, but including a battery storage system instead of the hydrogen sub-system. These analyses are also conducted according to the results obtained using the MFOA in its best performance over 30 independent runs, as it has revealed the highest efficiency among the MHOAs assessed.

\subsubsection{Dynamic payback period of the conceptualized $M G$}

The DPP method combines concepts from the classical static payback period technique and the discounted cash flow analysis (utilized in the NPC method) to identify the break-even date, after which a business plan is projected to be profitable considering the discount rate, which was first introduced by Irving Fisher [68]. The method can be adapted for application in the field of renewable energy system design and planning using the following equation:

$\sum_{t=0}^{D P P} S(1+i r)^{-t}-N P C_{T}=0$,

where $S$ represents the annual revenue created by selling energy to the consumers of the MG. Assuming a flat-rate electricity tariff of $\$ 0.16$ / $\mathrm{kWh}$ and a hydrogen price of $\$ 9.43 / \mathrm{kg}$ (in compliance with current renewable electricity and hydrogen rates in New Zealand), the value of $S$ can be calculated as:

$S=0.16 \times P_{L, \text { cum }}+9.43 \times P_{H T-S, \text { cum }}$,

where $P_{L, \text { cum }}$ and $P_{H T-S \text {, cum }}$ denote the cumulative sums of the supplied residential electrical loads $(\mathrm{kW})$ and the delivered hydrogen from the tank to the refuelling station $(\mathrm{kg})$, determined by the annual operation of the MG, which are found to be $3.703859 \mathrm{GWh} /$ year and 9.227 tonnes $\mathrm{H}_{2}$ /year (equivalent to $366.312 \mathrm{MWh}$ /year). The graphical discounted break-even analysis of the proposed system to be implemented at the case study site on the basis of the 20 -year revenue stream is presented

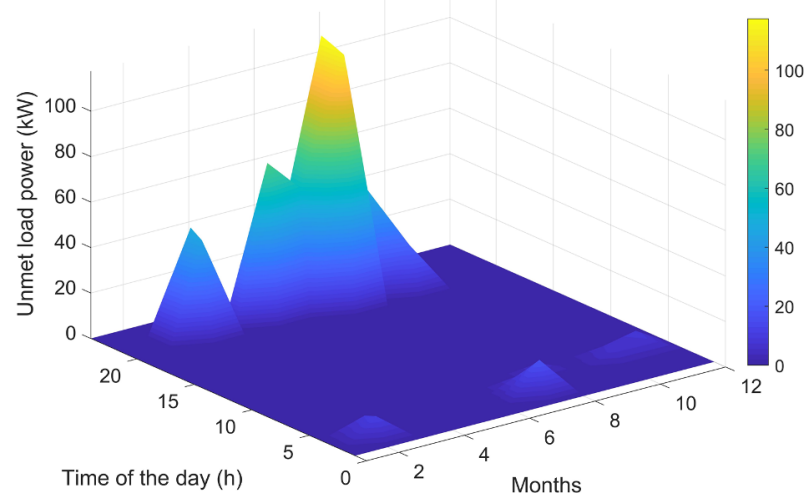

Fig. 14. Monthly mean daily profile for the aggregate loss of electrical and hydrogen loads. 


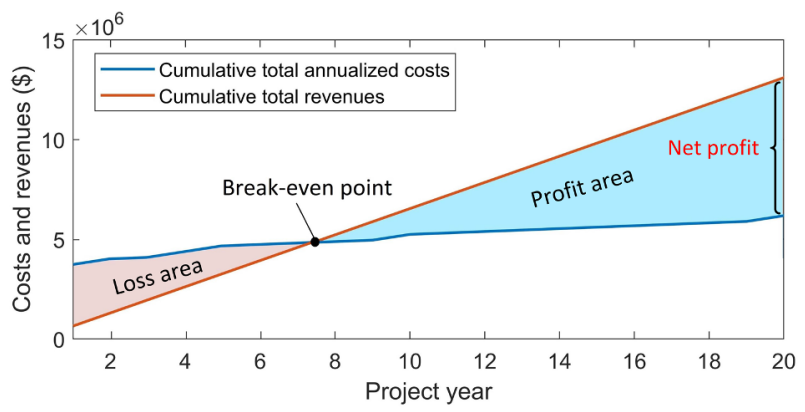

Fig. 15. Discounted break-even analysis of the project over a 20-year operating life-cycle period.

in Fig. 15. As illustrated in the figure, the discounted payback period of the project, if realized, would be 7.59 years. Furthermore, the discounted net profit that can be gained over the planning horizon, through the sale of green electricity and hydrogen, is anticipated to be $\$ 8,134,808$. It must be noted that the linearity of the cumulative total revenues curve is due to the simplifying assumption that load demand is constant over the projected lifetime of the programme. On the other hand, the nonlinearity of the cumulative total annualized costs curve is attributable to the O\&M costs, as well as the costs associated with the replacement of the components, whose lifetimes are over. In order to obtain the cumulative total annualized costs curve, we first calculated the total annualized capital cost and then added the discounted replacement (taking into account the salvage values) and O\&M costs to the years they are incurred. Accordingly, the cumulative total annualized costs curve uncovers the relatively low contribution of O\&M and replacement costs to the total NPC of the MG, compared with the capital cost of the system. The total annualized capital cost of the MG is calculated by multiplying the capital recovery factor by the total capital cost of the system, according to the formulation of the discounted cash flow principles put forward by Agalgaonkar et al. [69]. Also, notice that the cumulative sum of the total annualized costs at the end of the investment horizon is equal to the best total NPC obtained by the MFOA, which was found to be $\$ 5,780,909$ in sub-section 4.2 . The discounted break-even analysis indicates that the project not only is financially profitable, but also can be represented as a high-yield, low-risk investment opportunity due to its relatively short payback period.

4.4.2. Verification of the financial viability of the hydrogen energy storage

In order to verify the cost-effectiveness of the hydrogen energy backup sub-systems to be employed in the isolated MG networks to take advantage of their high overall energy storage efficiency in the medium- and long-term, a scenario analysis is conducted in this subsection. In this respect, the hydrogen sub-system of the MG structure, shown in Fig. 1, is entirely substituted by battery packs and the system is optimized at the investment planning phase using the proposed equipment capacity planning method. To this end, the base case scenario is compared with two alternative scenarios, where some commercially available, off-the-shelf LA and lithium-ion (Li-ion) batteries are separately incorporated in the system. The technical feasibility of these battery technologies has been widely demonstrated by several studies. Nevertheless, there exists some controversy in the literature concerning the cost-effectiveness of either technology for off-grid applications [70-73].

The following points must be noted:

1. Scenario 1 refers to the base case scenario (i.e. the hydrogen-based MG), while scenario 2 and scenario 3 respectively refer to the LAand Li-ion-battery-assisted MG structures illustrated above.

2. The Surrette 6-CS-25P, which is a flooded deep-cycle LA battery, manufactured by Rolls Battery Engineering is selected in scenario 2, whose techno-economic specifications are as follows [74]: capital 
cost $=\$ 930 /$ pack, replacement cost $=\$ 900 /$ pack, O\&M cost $=$ $\$ 7.5 /$ pack $/$ year, expected lifetime $=4$ years, minimum state-ofcharge $=40 \%$, round-trip efficiency $=80 \%$, weight $=144 \mathrm{~kg}$, and maximum capacity per pack $=7.5 \mathrm{kWh}$.

3. In scenario 3, a generic Li-ion battery bank takes the responsibility of backing up the intermittent RESs - together with the SCs - whose techno-economic specifications are as follows $[71,75]$ : capital cost $=\$ 630 / \mathrm{kWh}$, replacement cost $=\$ 600 / \mathrm{kWh}, \mathrm{O} \& \mathrm{M}$ cost $=\$ 20 /$ $\mathrm{kWh}$ /year, expected lifetime $=12$ years, average weight per capacity (inverse energy density) $=12.2 \mathrm{~kg} / \mathrm{kWh}$, minimum state-ofcharge $=10 \%$, and round-trip efficiency $=90 \%$.

4. Although the hydrogen-backup sub-system is removed from the MG in scenarios 2 and 3, an electrolyser is still required for satisfying the demand for hydrogen of the refuelling station. Also, the optimization protocol is given the discretion to decide whether or not to use a hydrogen reservoir for meeting the hydrogen demand of the station.

5. Unlike most other research efforts carried out in this area, the selfdischarge rates of the batteries are taken into consideration to reflect the medium- and long-term consequences of energy storage in batteries. The self-discharge rate of the LA batteries is estimated as $5 \%$ per month (i.e. one of the lowest rates among various battery technologies), while this rate for the Li-ion batteries is estimated as $5 \%$ in $24 \mathrm{~h}$, then $2 \%$ per month, plus $3 \%$ per month for their safety circuits [76].

6. The MFOA is adopted in scenario 2 and scenario 3 to optimize the system with the same parameters as those selected in the base scenario.

7. As per the base case scenario, the simulation is repeated for 30 independent runs and the results of the best trials are reported for both the second and third scenarios.

Table 6 compares the results of different scenarios mentioned above. The table indicates that employing the LA and Li-ion battery technologies to provide backup power, along with the SCs, reduces the total NPC of the project with cost savings of up to $\sim 13 \%$ and $\sim 8 \%$, respectively, compared with the base case scenario. However, one aspect that should not be overlooked in such cases is the environmental footprints of batteries throughout and after the end of their service lives.

The LA batteries are principally composed of lead as the anode, lead dioxide as the cathode, and sulphuric acid solution. Lead is a highly toxic heavy metal, while the sulphuric acid electrolytes solution is corrosive and highly reactive. Hence, the LA batteries can cause irreparable damage to the ecosystem, if they are disposed of without being subjected to decontamination processes. Proper recycling of the LA batteries, as well as recovery of their materials, are suggested as the most effective ways of mitigating their negative environmental effects $[77,78]$. However, it is interesting to note that battery-recycling facilities find meeting modern standards on lead emissions control unaffordable and are closing. As an example, the Petone, New Zealand Battery Recycling Facility, which was located nearby the considered case study site in this paper, closed in 2012 for this reason [79]. This has also raised concerns regarding the proliferation of unlicensed, small-scale recyclers (especially in developing countries due to the lack of adequate regulation and supervision). These centres not only have low recovery rates, but more importantly, put the health of all those living nearby these facilities (and especially their workers) in serious danger. For example, in China, approximately $95 \%$ of overall lead emissions from LA batteries are released in their end-of-life phase, resulting in a human toxicity potential of about $90 \%$ [77].

Nearly the same challenges hold for the Li-ion batteries, which contain high levels of lithium, cobalt, copper, and aluminium [70]. Although these types of batteries are associated with much lower toxicity issues than the LA batteries, they can still pose health risks. Therefore, they should also undergo appropriate treatment to meet the minimum pollution standards criteria when being recycled. Special arrangements might need to be considered to collect them for decontamination before disposal, when their service lives are over. The estimated cost for the eco-friendly disposal of the LA batteries are of the order of $\$ 5.50 / \mathrm{kg}$ (excluding tax and collection charges), while this value rises to $\$ 8.80 / \mathrm{kg}$ for Li-ion batteries - owing to the pragmatic requirements of special arrangements needed to address toxic gas emissions (such as fluoride) from Li-ion batteries at their disposal phase [80-83]. Not to mention that the costs associated with the safe recycling of both the LA and Li-ion batteries are greater than that of their green disposal [84].

Based on the above premises, in order to further validate the financial sustainability of the conceptualized hydrogen-assisted MG model, an inverse sensitivity analysis is carried out to identify the value of the cost per $\mathrm{kg}$ of the environmentally friendly battery disposal, at which the total NPCs of the battery-SC backed-up MGs would be equal to that of the conceptualized hydrogen-SC backed-up system. In this regard, we first added a weight-based cost component (as an unknown variable) to the costs associated with the LA and Li-ion batteries to include the costs of green disposal management programmes (hereafter termed 'sustainable battery cost') in their whole-life cost projections. Note that the energy-per-weight $(\mathrm{kWh} / \mathrm{kg})$ ratings of the LA and Li-ion battery types are presented in notes 2 and 3 above. We then varied the sustainable battery costs from 0 to 10 , in intervals of 0.1 for each battery type, whilst keeping all the other parameters unchanged. Finally, we solved the conceptualized MG's equipment capacity planning problem for each sustainable battery cost factor using the proposed method. Based on the best results obtained after 30 trials for each optimization task using the MFOA (by approximating the sustainable battery cost up to an accuracy of the first decimal place), we found the total NPCs of the battery-aided MG models are closest to the projected cost estimates for realizing the hybrid hydrogen-SC backed-up MG model at the sustainable battery costs of $\$ 4.19 / \mathrm{kg}$ and $\$ 8.66 / \mathrm{kg}$, respectively for the LA- and Li-ion-battery-assisted systems. More specifically, we found that although the optimal combinations of the sizes of the system components are nearly the same as those of the second and third scenarios (with no environmentally friendly battery disposal/recycling policies), the total NPCs of the battery-backed systems rise by up to $\sim 14 \%$ (i.e. $\$ 5,774,059$ ) and $\sim 8 \%$ (i.e. $\$ 5,776,033$ ) respectively for the LA- and Li-ion-battery-supported MG networks, when incorporating the effect of sustainable battery costs in the analysis. Note that the LA batteries will need to be replaced four times over the planning horizon, whereas the Li-ion batteries are more durable and will need to be replaced only once, in the 12th year of the project.

As the above discussion indicates, the eco-design of stand-alone battery backed-up MGs (which impose reasonable costs on the system to make batteries sustainable), when coupled with modelling of the selfdischarge rates of the batteries, results in an important change in our understanding of the economic feasibility of the battery-assisted sustainable energy systems. The most compelling evidence comes from the obtained values for the sustainable battery cost factors (from the inverse sensitivity analysis), which make the total NPCs of the batterybacked MGs nearly equal to that of the hydrogen-based MG, which are lower than what exists in practice (i.e. $\$ 5.50 / \mathrm{kg}$ and $\$ 8.80 / \mathrm{kg}$ respectively for the LA and Li-ion batteries). That is, the life-cycle costs of the LA- and Li-ion battery-backed MGs, when leveraging the (actual) battery sustainability costs, are as high as $\$ 6,089,231$ and $\$ 5,801,927$, respectively, which are higher than the conceptualized system's projected whole-life cost (i.e. $\$ 5,780,909$ ), albeit by a small margin especially in the case of the Li-ion battery backed-up system. Add to this the rapidly falling costs of the hydrogen technologies, whereas the battery storage is considered to be a mature technology, at least in the case of the LA batteries.

From Table 6, one can also note that the optimal solution sets in scenarios 2 and 3 avoided the hydrogen tank, and also determined the same capacity for the hydrogen station as that found in the base case scenario. This can be ascribed to the identification of the on-demand 
production of hydrogen (which eliminates the need for a reservoir) to be the optimal strategy for supplying the fuel cell-powered trucks and tractors by the optimization protocol, similarly as in scenario 1 . Also, notice that the allocated capacity to the electrolyser in scenario 2 and scenario 3 to address the hydrogen loads remains idle under no- $\mathrm{H}_{2}$-load conditions ( $24 \mathrm{~h}$ a day on weekends and between $6 \mathrm{am}$ and $11 \mathrm{pm}$ on weekdays), whereas the capacity of the electrolyser in scenario 1 is determined based upon the synergy between the hydrogen loading and hydrogen backup system to fully exploit its potential, making it a more viable solution.

\section{Conclusions}

This paper has put forward a metaheuristic-based modelling approach for the optimal design and capacity planning of eco-efficient grid-independent micro-grids, whilst attempting to highlight the need for examining the performance of newly emerged metaheuristic optimization algorithms in solving the optimal micro-grid design and capacity planning problems. Accordingly, the performances of six recent metaheuristic optimization algorithms are compared with well-documented metaheuristic optimization algorithms in this research area (i.e. the genetic algorithm and the particle swarm optimization). A grid-independent hydrogen-based micro-grid test-case system, developed to provide sustainable, carbon-free energy to 350 people in the Feilding area, New Zealand, is used to evaluate the performances of the considered metaheuristic optimization algorithms, and the comparative results are presented. The conceptualized micro-grid structure provides a holistic framework to facilitate the agricultural and forestry waste management programmes, whilst additionally improving the resilience of power supply to remote communities through an efficient integration of super-capacitors that enhance the transient stability of the system (by compensating for the low power density of polymer electrolyte membrane fuel cells); in line with the objectives of sustainable development. Indeed, hybridization of fuel cells with super-capacitors allows for leveraging the high energy/power density capability of fuel cells/supercapacitors. The hydrogen-based micro-grid, conceptualized in this paper, also provides a platform for the (i) electrolytic hydrogen production using renewable energy sources, and (ii) hydrogen production through low-grade biomass gasification-based methanation procedures, in order to serve the considered heavy-duty vehicles and provide an efficient energy storage medium in the mid- to long-term; hence, it paves the way towards the realization of a green and sustainable hydrogen energy economy. An innovative energy management scheme is also devised to cost-effectively integrate the challenging hydrogen loads required to refuel the fuel cell-powered trucks and tractors into the proposed system, thus effectively contributing to the agricultural and transport sustainability targets. The high degree of diversification in renewable energy sources employed within the configuration of the conceptualized micro-grid network safeguards the energy security. Further, numerical simulation results indicate that the levelized costs of electricity and hydrogen of the proposed micro-grid model for the studied site are lower than the current tariffs for sustainable electricity and hydrogen by up to $\sim 33 \%$ and $\sim 51 \%$, respectively. In addition, the discounted payback period of the planned micro-grid project is calculated to be 7.59 years, with a net profit of about 1.41 times the total investment required, making it highly attractive to investors. These results are achieved without considering any policy support mechanisms to assist investors with this renewable energy project, which is another indication of the significance of the proposed modelling framework for the optimal design and equipment capacity planning of micro-grids, and also the conceptualized system.

In summary, based on the validated numeric simulation results, the following general conclusions can be drawn:

1. The moth-flame optimization algorithm outperforms the genetic algorithm, the particle swarm optimization, the dragonfly algorithm, the salp swarm algorithm, the ant lion optimizer, the grey wolf optimizer, and the grasshopper optimization algorithm for micro-grid optimum design applications in terms of the solution quality, but its strong exploitation capability in the last iterations slows down its convergence speed, which is not very critical because the problem at hand belongs to the domain of long-term energy infrastructure planning, meaning that long computational run times are tolerable so long as the numerical tractability is preserved. In fact, this strong exploitation capability of the moth-flame optimization algorithm in the last iterations can be considered as its advantage in this research context.

2. The life-cycle cost of a hybrid fuel cell-super-capacitor back-up system, when integrated into stand-alone micro-grids to support the intermittent power outputs from weather-dependent renewable energy technologies, is comparable to hybrid battery-super-capacitor energy storage systems if appropriate penalties on the commonly neglected recycling aspects of battery storage technologies are considered, and the inability of batteries in efficient long-term energy storage (due to their elevated self-discharge rates for long-run applications), are adhered to.

3. Considering multiple types of each component with different nominal capacities can lead to a better design for the system, through benefitting from both the lower unitary costs of the components with higher capacities, and the advantageous feature of the components with lower capacities in preventing the waste of money owing to overestimating the required capacities of components in the marginal points.

While the superiority of an enhanced variant of a metaheuristic algorithm to its original version may not be guaranteed in every application, there is always the prospect that a newly emerged variant could result in a substantial improvement in nearing the global optima - by fine-tuning the exploration-exploitation trade-offs. In this respect, a further comparative evaluation of the moth-flame optimization algorithm's efficiency with those of its state-of-the-art improved variants has revealed that the currently available variants of the moth-flame optimization algorithm have yet to be improved upon so as to have a real impact on the optimality of the solution in the context of the microgrid design and planning.

\section{Limitations and future work}

The research has two limitations. The first is that the performances of the studied metaheuristic optimization algorithms are compared using only one micro-grid test-case system. The second is that only a small fraction of the new metaheuristic optimization algorithms are examined in this study for solving an optimal micro-grid planning problem.

In order to fulfil the above-mentioned limitations of this study, new metaheuristic optimization algorithms need to be applied to the considered problem on a wider scale. Also, the performances of the optimization algorithms need to be evaluated based on their results, when applied to different micro-grid configurations with various renewable generation and/or storage technologies and different grid-connection layouts; i.e. grid-connected and islanded.

Furthermore, the typology selection technique, proposed in this study for selecting the typology of wind turbines, can be extended and adapted to other components of the system. Additionally, a broad comparison of the typologies of the system components (not just among two product models) could be made by pursuing the typology selection strategy proposed in this study. Further research could also be carried out to investigate the sensitivity of the optimum back-up system type (i.e. hydrogen-based vs. battery storage), which is accompanied by super-capacitors, relative to different electric and hydrogen loading levels in the context of the conceptualized micro-grid configuration. Another direction for future research would be to establish a platform 
to study the harmonic emissions arising from the power converters tying the loads/distributed energy resources to the system's common bus, while optimally planning a grid-independent micro-grid system with a multi-objective approach - where the system's whole-life cost minimization and power quality maximization could be considered as two conflicting objectives of the optimization problem. Further research is also needed to leverage the co-generation potential of fuel cells - which could provide effective electricity and district heating solutions when accompanied by auxiliary heating and thermal storage systems - to harness the full benefits of the proposed system through increasing its overall energy efficiency - as the final step towards planning a sustainable, energy-independent future for remote communities, which are located in relatively cold regions and have agricultural economies.

\section{Appendix A. Supplementary material}

Supplementary data to this article can be found online at https:// doi.org/10.1016/j.apenergy.2019.114224.

\section{References}

[1] Ehsan A, Yang Q. Optimal integration and planning of renewable distributed generation in the power distribution networks: a review of analytical techniques. Appl Energy 2018;210:44-59. https://doi.org/10.1016/j.apenergy.2017.10.106.

[2] Moghaddas-Tafreshi SM, Jafari M, Mohseni S, Kelly S. Optimal operation of an energy hub considering the uncertainty associated with the power consumption of plug-in hybrid electric vehicles using information gap decision theory. Int J Electr Power Energy Syst 2019;112:92-108. https://doi.org/10.1016/j.ijepes.2019.04. 040.

[3] Ton DT, Smith MA. The U.S. Department of Energy's Microgrid Initiative. Electr J 2012;25(8):84-94. https://doi.org/10.1016/j.tej.2012.09.013.

[4] Maleki A, Pourfayaz F. Optimal sizing of autonomous hybrid photovoltaic/wind/ battery power system with LPSP technology by using evolutionary algorithms. Sol Energy 2015;115:471-83. https://doi.org/10.1016/j.solener.2015.03.004.

[5] Gamarra C, Guerrero JM. Computational optimization techniques applied to microgrids planning: a review. Renew Sustain Energy Rev 2015;48:413-24. https:/ doi.org/10.1016/j.rser.2015.04.025.

[6] Radosavljević J. Metaheuristic Optimization in Power Engineering. London, UK: The Institution of Engineering and Technology (IET). ISBN: 978-1-78561-546-7.

[7] Al-falahi MDA, Jayasinghe SDG, Enshaei H. A review on recent size optimization methodologies for standalone solar and wind hybrid renewable energy system. Energy Convers Manag 2017;143:252-74. https://doi.org/10.1016/j.enconman. 2017.04.019.

[8] Hakimi SM, Tafreshi SMM, Kashefi A. Unit sizing of a stand-alone hybrid power system using Particle Swarm Optimization (PSO). In: Proceedings of the 2007 IEEE international conference on automation and logistics, Jinan, China, 18-21 Aug. 2007. p. 3107-12. https://doi.org/10.1109/ICAL.2007.4339116.

[9] Li B, Roche R, Paire D, Miraoui A. Sizing of a stand-alone microgrid considering electric power, cooling/heating, hydrogen loads and hydrogen storage degradation. Appl Energy 2017;205:1244-59. https://doi.org/10.1016/j.apenergy.2017.08.142.

[10] Ghorbani N, Kasaeian A, Toopshekan A, Bahrami L, Maghami A. Optimizing a hybrid wind-PV-battery system using GA-PSO and MOPSO for reducing cost and increasing reliability. Energy 2017;154:581-91. https://doi.org/10.1016/j.energy. 2017.12.057.

[11] Derakhshan G, Shayanfar HA, Kazemi A. Optimal design of solar PV-WT-SB based smart microgrid using NSHCSO. Int J Hydrogen Energy 2016;41(44):19947-56. https://doi.org/10.1016/j.ijhydene.2016.08.085.

[12] Chauhan A, Saini RP. Discrete harmony search based size optimization of Integrated Renewable Energy System for remote rural areas of Uttarakhand state in India. Renew Energy 2016;94:587-604. https://doi.org/10.1016/j.renene.2016.03.079.

[13] Nasiraghdam H, Jadid S. Optimal hybrid PV/WT/FC sizing and distribution system reconfiguration using multi-objective artificial bee colony (MOABC) algorithm. Sol Energy 2012;86(10):3057-71. https://doi.org/10.1016/j.solener.2012.07.014.

[14] Fetanat A, Khorasaninejad E. Size optimization for hybrid photovoltaic-wind energy system using ant colony optimization for continuous domains based integer programming. Appl Soft Comput J 2015;31:196-209. https://doi.org/10.1016/j.asoc. 2015.02.047.

[15] Kefayat M, Lashkar Ara A, Nabavi Niaki SA. A hybrid of ant colony optimization and artificial bee colony algorithm for probabilistic optimal placement and sizing of distributed energy resources. Energy Convers Manag 2015;92:149-61. https://doi. org/10.1016/j.enconman.2014.12.037.

[16] Mohandas N, Balamurugan R, Lakshminarasimman L. Optimal location and sizing of real power DG units to improve the voltage stability in the distribution system using ABC algorithm united with chaos. Int J Electr Power Energy Syst 2015;66:41-52. https://doi.org/10.1016/j.ijepes.2014.10.033.

[17] Jiao Y, Wu J, Tan QK, Tan ZF, Wang G. An optimization model and modified harmony search algorithm for microgrid planning with ESS. Discret Dyn Nat Soc 2017;2017. https://doi.org/10.1155/2017/8425458. Article ID 8425458.
[18] Sheng S, Zhang J. Capacity configuration optimisation for stand-alone micro-grid based on an improved binary bat algorithm. J Eng 2017;2017(13):2083-7. https:// doi.org/10.1049/joe.2017.0696.

[19] Wolpert DH, Macready WG. No free lunch theorems for optimization. IEEE Trans Evol Comput 1997;1(1):67-82. https://doi.org/10.1109/4235.585893.

[20] Adefarati T, Bansal RC. Reliability, economic and environmental analysis of a microgrid system in the presence of renewable energy resources. Appl Energy 2019;236:1089-114. https://doi.org/10.1016/j.apenergy.2018.12.050.

[21] Obara S, Hamanaka R, El-Sayed AG. Design methods for microgrids to address seasonal energy availability - a case study of proposed Showa Antarctic Station retrofits. Appl Energy 2019;236:711-27. https://doi.org/10.1016/j.apenergy.2018. 12.031.

[22] Mirjalili S. Moth-flame optimization algorithm: a novel nature-inspired heuristic paradigm. Knowledge-Based Syst 2015;89:228-49. https://doi.org/10.1016/j. knosys.2015.07.006.

[23] Mirjalili S. Dragonfly algorithm: a new meta-heuristic optimization technique for solving single-objective, discrete, and multi-objective problems. Neural Comput Appl 2016;27(4):1053-73. https://doi.org/10.1007/s00521-015-1920-1.

[24] Mirjalili S, Gandomi AH, Mirjalili SZ, Saremi S, Faris H, Mirjalili SM. Salp Swarm Algorithm: a bio-inspired optimizer for engineering design problems. Adv Eng Softw 2017;114:163-91. https://doi.org/10.1016/j.advengsoft.2017.07.002.

[25] Mirjalili S. The ant lion optimizer. Adv Eng Softw 2015;83:80-98. https://doi.org/ 10.1016/j.advengsoft.2015.01.010.

[26] Mirjalili S, Mirjalili SM, Lewis A. Grey wolf optimizer. Adv Eng Softw 2014;69:46-61. https://doi.org/10.1016/j.advengsoft.2013.12.007.

[27] Saremi S, Mirjalili S, Lewis A. Grasshopper optimisation algorithm: theory and application. Adv Eng Softw 2017;105:30-47. https://doi.org/10.1016/j. advengsoft.2017.01.004

[28] Goldberg DE, Holland JH. Genetic algorithms and machine learning. Mach Learn 1988;3:95-9. https://doi.org/10.1023/A:1022602019183.

[29] Sivanandam SN, Deepa SN. Introduction to Genetic Algorithms., Berlin, Heidelberg: Springer-Verlag; 2008. https://doi.org/10.1007/978-3-540-73190-0.

[30] Kennedy J, Eberhart RC. Particle swarm optimization. In: Proceedings of the 1995 IEEE international conference on neural networks, Perth, WA, Australia, 27 Nov.-1 Dec. 1995, vol. 4. p. 1942-8. https://doi.org/10.1109/ICNN.1995.488968.

[31] González A, Riba J, Rius A, Puig R. Optimal sizing of a hybrid grid-connected photovoltaic and wind power. Appl Energy 2015;154:752-62. https://doi.org/10. 1016/j.apenergy.2015.04.105.

[32] Li W, Mou X, Zhou Y, Marnay C. On voltage standards for DC home microgrids energized by distributed sources. In: Proceedings of the 7th international power electronics and motion control conference, Harbin, China, 2-5 Jun. 2012, vol. 3. p. 2282-6. https://doi.org/10.1109/IPEMC.2012.6259203.

[33] Duman AC, Güler Ö. Techno-economic analysis of off-grid PV/wind/fuel cell hybrid system combinations with a comparison of regularly and seasonally occupied households. Sustain Cities Soc 2018;42:107-26. https://doi.org/10.1016/j.scs. 2018.06.029.

[34] Li C, Liu Y, Li G, Li J, Zhu D, Jia W, et al. Evaluation of wind energy resource and wind turbine characteristics at two locations in China. Technol Soc 2016;47:121-8. https://doi.org/10.1016/j.techsoc.2016.09.003.

[35] Amrollahi MH, Bathaee SMT. Techno-economic optimization of hybrid photovoltaic/wind generation together with energy storage system in a stand-alone micro-grid subjected to demand response. Appl Energy 2017;202:66-77. https:// doi.org/10.1016/j.apenergy.2017.05.116.

[36] Basir Khan MR, Jidin R, Pasupuleti J. Multi-agent based distributed control architecture for microgrid energy management and optimization. Energy Convers Manag 2016;112:288-307. https://doi.org/10.1016/j.enconman.2016.01.011.

[37] Mohseni S, Moghaddas-Tafreshi SM. A multi-agent system for optimal sizing of a cooperative self-sustainable multi-carrier microgrid. Sustain Cities Soc 2018;38:452-65. https://doi.org/10.1016/j.scs.2018.01.016.

[38] Xu F, Liu J, Lin S, Dai Q, Li C. A multi-objective optimization model of hybrid energy storage system for non-grid-connected wind power: a case study in China. Energy 2018;163:585-603. https://doi.org/10.1016/j.energy.2018.08.152.

[39] Hakimi SM, Moghaddas-Tafreshi SM. Optimal sizing of a stand-alone hybrid power system via particle swarm optimization for Kahnouj area in south-east of Iran. Renew Energy 2009;34(7):1855-62. https://doi.org/10.1016/j.renene.2008.11. 022.

[40] Yamada N, Mohamad MNA. Efficiency of hydrogen internal combustion engine combined with open steam Rankine cycle recovering water and waste heat. Int J Hydrogen Energy 2010;35(3):1430-42. https://doi.org/10.1016/j.ijhydene.2009. 11.088 .

[41] Anonymous, "New Holland's NH2 fuel cell powered tractor to enter service," Fue Cells Bull 2012; 2012 (1):3-4. https://doi.org/10.1016/S1464-2859(12)70004-4.

[42] Anonymous, "Hyundai and H2 Energy to launch world's first fleet of Fuel Cell Truck," 2018. [Online]. Available: https://www.hyundai.news/uk/model-news/ hyundai-motor-and-h2-energy-will-bring-the-worlds-first-fleet-of-fuel-cell-electric truck-into-commercial-operation/ [Accessed: 15-Jul.-2019].

[43] Akram U, Khalid M, Shafiq S. An innovative hybrid wind-solar and battery-supercapacitor microgrid system-development and optimization. IEEE Access 2017;5:25897-912. https://doi.org/10.1109/ACCESS.2017.2767618.

[44] Billinton R, Allan RN. Reliability evaluation of engineering systems: concepts and techniques, 2nd ed. New York: Plenum Press; 1992. https://doi.org/10.1007/978 1-4899-0685-4.

[45] Mavrotas G, Florios K, Vlachou D. Energy planning of a hospital using Mathematical Programming and Monte Carlo simulation for dealing with uncertainty in the economic parameters. Energy Convers Manag 2010;51(4):722-31. https://doi.org/ 10.1016/j.enconman.2009.10.029. 
[46] Kashefi-Kaviani A, Riahy GH, Kouhsari SM. Optimal design of a reliable hydrogenbased stand-alone wind/PV generating system, considering component outages. Renew Energy 2009;34(11):2380-90. https://doi.org/10.1016/j.renene.2009.03. 020 .

[47] CliFlo: NIWA's National Climate Database on the Web. [Data Collection]. Available: http://cliflo.niwa.co.nz/. [Retrieved: 19-Dec.-2018].

[48] Anderson B, Eyers D, Ford R, Ocampo DG, Peniamina R, Stephenson J, et al. New Zealand GREEN Grid Household Electricity Demand Study 2014-2018. [Data Collection]. Colchester, Essex: UK Data Service. http://dx.doi.org/10.5255/UKDASN-853334.

[49] Teetz HW, Harms TM, von Backström TW. Assessment of the wind power potential at SANAE IV base, Antarctica: a technical and economic feasibility study. Renew Energy 2003;28(13):2037-61. https://doi.org/10.1016/S0960-1481(03)00076-4.

[50] Abdelkader A, Rabeh A, Mohamed Ali D, Mohamed J. Multi-objective genetic algorithm based sizing optimization of a stand-alone wind/PV power supply system with enhanced battery/supercapacitor hybrid energy storage. Energy 2018;163:351-63. https://doi.org/10.1016/j.energy.2018.08.135.

[51] Cao S, Alanne K. The techno-economic analysis of a hybrid zero-emission building system integrated with a commercial-scale zero-emission hydrogen vehicle. Appl Energy 2018;211:639-61. https://doi.org/10.1016/j.apenergy.2017.11.079.

[52] Xu X, Xu B, Dong J, Liu X. Near-term analysis of a roll-out strategy to introduce fuel cell vehicles and hydrogen stations in Shenzhen China. Appl Energy 2017;196:229-37. https://doi.org/10.1016/j. apeneroy 2016.11.048.

[53] Nistor S, Dave S, Fan Z, Sooriyabandara M. Technical and economic analysis of hydrogen refuelling. Appl Energy 2016;167:211-20. https://doi.org/10.1016/j. apenergy.2015.10.094.

[54] Grüger F, Dylewski L, Robinius M, Stolten D. Carsharing with fuel cell vehicles: sizing hydrogen refueling stations based on refueling behavior. Appl Energy 2018;228:1540-9. https://doi.org/10.1016/j.apenergy.2018.07.014.

[55] Moghaddas-Tafreshi SM, Mohseni S, Karami ME, Kelly S. Optimal energy management of a grid-connected multiple energy carrier micro-grid. Appl Therm Eng 2019;152:796-806. https://doi.org/10.1016/j.applthermaleng.2019.02.113.

[56] Federal Reserve Statistical Release: Foreign Exchange Rates (Annual). [Data Collection]. Available: http://www.federalreserve.gov/releases/g5a/. [Retrieved: 19-Jan.-2019].

[57] Veček N, Črepinšek M, Mernik M. On the influence of the number of algorithms, problems, and independent runs in the comparison of evolutionary algorithms. Appl Soft Comput J 2017;54:23-45. https://doi.org/10.1016/j.asoc.2017.01.011.

[58] Taher MA, Kamel S, Jurado F, Ebeed M. An improved moth-flame optimization algorithm for solving optimal power flow problem. Int Trans. Electr Energy Syst 2019;29(3):e2743https://doi.org/10.1002/etep.2743.

[59] Mohamed A-AA, Mohamed YS, El-Gaafary AAM, Hemeida AM. Optimal power flow using moth swarm algorithm. Electr Power Syst Res 2017;142:190-206. https:// doi.org/10.1016/j.epsr.2016.09.025.

[60] Mohamed EA, Mohamed A-AA, Mitani Y. Hybrid GMSA for optimal placement and sizing of distributed generation and shunt capacitors. J Eng Sci Technol Rev 2018;11(1):55-65https://doi.org/10.25103/jestr.111.07.

[61] Ullah I, Hussain S. Time-constrained nature-inspired optimization algorithms for an efficient energy management system in smart homes and buildings. Appl Sci 2019;9(4):792. https://doi.org/10.3390/app9040792.

[62] Sayed GI, Hassanien AE. A hybrid SA-MFO algorithm for function optimization and engineering design problems. Complex Intell Syst 2018;4(3):195-212. https://doi. org/10.1007/s40747-018-0066-z.

[63] Khalilpourazari S, Khalilpourazary S. An efficient hybrid algorithm based on Water Cycle and Moth-Flame Optimization algorithms for solving numerical and constrained engineering optimization problems. Soft Comput 2019;23(5):1699-722. https://doi.org/10.1007/s00500-017-2894-y.

[64] Udomkasemsub O, Akkarajitsakul K, Achalakul T. Hybrid moth-flame and salp swarm optimization algorithm. Int J Model Optim 2019;9(4):223-9. https://doi. org/10.7763/IJMO.2019.V9.713.
[65] Lotfi H, Khodaei A. Levelized cost of energy calculations for microgrids. In: Proceedings of the 2016 IEEE Power Energy Soc. Gen. Meet., Boston, MA, USA, 17-21 Jul. 2016. p. 1-5. https://doi.org/10.1109/PESGM.2016.7741379.

[66] O'Neill B. Average Electricity Costs per kWh; 2018. Available: https://www. canstarblue.co.nz/energy/average-electricity-costs-per-kwh/ [Accessed: 15-Jul.2019].

[67] Watson M. Could hydrogen turn Taranaki into the Norway of the Pacific?; 2018. Available: https://www.stuff.co.nz/environment/105601987/could-hydrogenturn-taranaki-into-the-norway-of-the-pacific/ [Accessed: 15-Jul.-2019].

[68] Fisher I. The theory of interest, as determined by impatience to spend income and opportunity to invest it. New York: Macmillan; 1930.

[69] Agalgaonkar AP, Dobariya CV, Kanabar MG, Khaparde SA, Kulkarni SV. Optimal sizing of distributed generators in microgrid. In: Proceedings of the 2006 IEEE power India conf., New Delhi, India, 10-12 Apr. 2006. p. 901-8. https://doi.org/ 10.1109/POWERI.2006.1632627.

[70] Podder S, Khan MZR. Comparison of lead acid and Li-ion battery in solar home system of Bangladesh, In: Proceedings of the 2016 5th int. conf. informatics, elec tron. vision, ICIEV, Dhaka, Bangladesh, 13-14 May 2016. p. 434-8. https://doi. org/10.1109/ICIEV.2016.7760041.

[71] Husein M, Chung I-Y. Optimal design and financial feasibility of a university campus microgrid considering renewable energy incentives. Appl Energy 2018;225:273-89. https://doi.org/10.1016/j.apenergy.2018.05.036.

[72] Jaiswal A. Lithium-ion battery based renewable energy solution for off-grid electricity: a techno-economic analysis. Renew Sustain Energy Rev 2017;72:922-34. https://doi.org/10.1016/j.rser.2017.01.049.

[73] Keshan H, Thornburg J, Ustun TS. Comparison of lead-acid and lithium ion batteries for stationary storage in off-grid energy systems. In: Proceedings of the 4th IET clean energy and technology conference (CEAT 2016), Kuala Lumpur, Malaysia, 14-15 Nov. 2016. p. 1-7. https://doi.org/10.1049/cp.2016.1287.

[74] Rolls Battery Engineering, "BATTERY: 6 CS 25P," 2019. Available: http:// rollsbattery.com/battery/6-cs-25p/ [Accessed: 15-Jul.-2019].

[75] Berjoza D, Jurgena I. Influence of batteries weight on electric automobile performance. In: Proceedings of the 16th international scientific conference engineering for rural development, Jelgava, Latvia, 24-26 May 2017. p. 1388-94. https://doi. org/10.22616/ERDev2017.16.N316.

[76] Anonymous, BU-802b: What does Elevated Self-discharge Do?; 2018. Available: https://batteryuniversity.com/learn/article/elevating_self_discharge/. [Accessed: 15-Jul.-2019].

[77] Liu W, Sang J, Chen L, Tian J, Zhang H, Olvera Palma G. Life cycle assessment of lead-acid batteries used in electric bicycles in China. J Clean Prod 2015;108:1149-56. https://doi.org/10.1016/j.jclepro.2015.07.026.

[78] Zhang J, Chen C, Zhang X, Liu S. Study on the environmental risk assessment of lead-acid batteries. Procedia Environ Sci 2016;31:873-9. https://doi.org/10.1016/ j.proenv.2016.02.103.

[79] Anonymous, Plans to Close Petone Battery Recycling Facility; 2012. Available: http://www.scoop.co.nz/stories/BU1202/S00505/plans-to-close-petone-batteryrecycling-facility.htm/ [Accessed: 15-Jul.-2019].

[80] Tonkin \& Taylor Ltd. Assessment of appropriate disposal options for household (dry cell) batteries. Report prepared for Auckland Council, T\&T Ref: 29540, Nov. 2013.

[81] MRI e-cycle solutions. Recycling fees. [Data Collection]. Available: https://mri. com.au/. [Retrieved: 18-Jul.-2019].

[82] Nedjalkov A, Meyer J, Köhring M, Doering A, Angelmahr M, Dahle S, et al. Toxic gas emissions from damaged lithium ion batteries-analysis and safety enhancement solution. Batteries 2016;2(1):5. https://doi.org/10.3390/batteries2010005

[83] Larsson F, Andersson P, Blomqvist P, Mellander B-E. Toxic fluoride gas emissions from lithium-ion battery fires. Sci Rep 2017;7. https://doi.org/10.1038/s41598017-09784-z. Article number: 10018.

[84] Birke KP. Modern Battery Engineering: A Comprehensive Introduction World Scientific Pub. Co. Inc., Apr. 2019. https://doi.org/10.1142/11039. 